Research Article

\title{
Adsorption Behaviour and Kinetics of Zearalenone on Hydroxyl-Fe-Al-Intercalated Montmorillonite
}

\author{
Shengqiong Fang, ${ }^{1}$ Yueqi Xiao, ${ }^{1}$ and Huiqiang Wang $\mathbb{D}^{2}$ \\ ${ }^{1}$ Department of Environmental Science and Engineering, Fuzhou University, Fuzhou, Fujian 350108, China \\ ${ }^{2}$ College of Energy, Xiamen University, Xiamen 361102, China
}

Correspondence should be addressed to Huiqiang Wang; fzu_whq@163.com

Received 10 June 2020; Accepted 3 July 2020; Published 13 August 2020

Academic Editor: Tomonori Ohba

Copyright (C) 2020 Shengqiong Fang et al. This is an open access article distributed under the Creative Commons Attribution License, which permits unrestricted use, distribution, and reproduction in any medium, provided the original work is properly cited.

\begin{abstract}
Pristine montmorillonite (Mont) was used as raw materials to prepare hydroxyl-Fe-pillared Mont, hydroxyl-Al-pillared Mont, and hydroxyl-Fe-Al-pillared Mont composites. By varying the $\mathrm{OH} / \mathrm{Fe}$ and $\mathrm{Fe} / \mathrm{Al}$ molar ratios during the preparation of the pillared Mont, the adsorption capacity of zearalenone (ZEA) and the kinetics were elucidated. The characterization of X-ray diffraction (XRD) and Fourier transform infrared (FT-IR) spectroscopy reveals the adsorption mechanism of pristine and modified Mont. The results indicated that the ZEA adsorption capacity is Mont $(0.05 \mathrm{mg} / \mathrm{g})<<1.5 \mathrm{OH} / \mathrm{Fe}-\mathrm{Mont}(0.28 \mathrm{mg} / \mathrm{g})$ $<<\mathrm{OH} / \mathrm{Al}-\mathrm{Mont}(0.51 \mathrm{mg} / \mathrm{g})<0.5 \mathrm{Fe} / \mathrm{Al}-\mathrm{Mont}(0.56 \mathrm{mg} / \mathrm{g})$ in the condition of $\mathrm{pH}=8$ and $37^{\circ} \mathrm{C}$, in which both $0.5 \mathrm{Fe} / \mathrm{Al}-\mathrm{Mont}$ and $\mathrm{OH} / \mathrm{Al}$-Mont reached maximum adsorption capacity and 1.5OH/Fe-Mont attained 5 times the capacity of Mont. Adsorption isotherm studies revealed that Freundlich adsorption isotherms best represented the experimental data. The kinetic data for ZEA adsorption revealed that the Mont adsorption capacity for ZEA equilibrates in 1 hour and is best described using the pseudosecond-order rate equation. The XRD analysis indicated that the amplification of Fe-dominant pillared Mont interlayer spacing is the main reason for the observed increases in the adsorption capacity of ZEA, while Al-dominant pillared Mont has a relatively stable Keggin structure; therefore, interlayer spacing is not the primary mechanism for changes in the adsorption capacity of both $\mathrm{OH} / \mathrm{Al}-\mathrm{Mont}$ and Al-dominant pillared Mont. An FT-IR analysis demonstrated that cationic exchange was the dominant mechanism that allowed ZEA and hydroxyl-Al ions to enter the Mont interlayers, while this cationic exchange mechanism was not the dominant mechanism used by hydroxyl-Fe entering the Mont layers.
\end{abstract}

\section{Introduction}

Mycotoxins are toxic and harmful metabolites produced by fungus or mould in suitable conditions and mainly consist of aflatoxin, zearalenone, ochratoxin, and fumagillin [1-6]. According to a report released by the United Nations Food and Agriculture Organization, approximately $25 \%$ of crops globally are contaminated by mycotoxins, resulting in major economic losses [4]. In China, this contamination is in excess of $60-70 \%$, especially in the southern and eastern regions [7]. Therefore, resolving mycotoxin contamination of foodstuffs is a global challenge [8].

Zearalenone (ZEA) is one of the most prevalent mycotoxins in contaminated grain and is produced as a secondary metabolite by a variety of fungi within the Fusarium genus $[9,10]$. ZEA is a toxin that exhibits behaviour similar to oestrogen, which readily and irreversibly binds to intrauterine oestrogen receptors. This binding results in significant harm to the reproductive physiology of livestock, which calls for immediate mitigation strategies [11-13]. Currently, the removal of mycotoxins through both physical and chemical means destroys the nutritional contents in food, whereas biological treatments are time-consuming. Therefore, simple adsorption is considered to be the most effective method [14-16].

Montmorillonite (Mont), the main mineral component of bentonite, possesses a high ion exchange capacity due to the intrinsically layered structure of this mineral in which high-valence cations within voids are readily replaced with low-valence ions [17]. To date, most research has focused on 
the removal of ZEA through the use of organic cationmodified Mont, despite its environmental risks of organic cations. In contrast, there has been no report on the adsorption characteristics and mechanism of ZEA removal using inorganic hydroxyl-Fe-Al-composite-pillared Mont $[11,18,19]$.

The present study focused on the use of Mont, hydroxylFe-modified Mont (OH/Fe-Mont), hydroxyl-Al-modified Mont (OH/Al-Mont), and hydroxyl-Fe-Al compoundmodified Mont (Fe/Al-Mont) in the in vitro adsorption of ZEA, and the capacity of and applicable model for adsorption to both Mont and inorganically modified Mont were investigated. The effects of $\mathrm{pH}$, time, temperature, and ZEA initial concentration on the adsorption of ZEA were characterized by X-ray diffraction (XRD), Fourier transform infrared (FT-IR) spectroscopy, and other methods.

\section{Materials and Methods}

2.1. Experimental Materials. High purity ZEA standards and Mont were obtained from Sigma-Aldrich, USA; the ion exchange capacity (CEC) of Mont is $24.6 \mathrm{mmol} / 100 \mathrm{~g}$; the molecular formula of ZEA is $\mathrm{C}_{18} \mathrm{H}_{22} \mathrm{O}_{5}$, with a molecular weight of $318.36, \mathrm{pK}_{\mathrm{a} 1}$ of 7.62 , and a $\log K_{o w}$ of 3.66 [17]. All of the other reagents were purum or chromatography grade. A ZEA stock solution $(250 \mathrm{mg} / \mathrm{L})$ was prepared with a mixture of acetonitrile/methanol $(1: 1)$ and stored in the dark at $-20^{\circ} \mathrm{C}$; deionized water $(18 \mathrm{M} \Omega \cdot \mathrm{cm})$ was used in all experiments.

\subsection{Preparation of Pillared Mont Adsorbents}

(1) Hydroxyl-pillared Mont adsorbents were prepared as follows: a solution of $\mathrm{Fe}\left(\mathrm{NO}_{3}\right)_{3} \cdot 9 \mathrm{H}_{2} \mathrm{O}$ was prepared by dissolving $\mathrm{Fe}\left(\mathrm{NO}_{3}\right)_{3} \cdot 9 \mathrm{H}_{2} \mathrm{O}$ (24.24 g) in deionized water at $60^{\circ} \mathrm{C}$ with constant stirring, while various quantities of powdered $\mathrm{Na}_{2} \mathrm{CO}_{3}$ (0.64 g, $1.27 \mathrm{~g}, 1.91 \mathrm{~g}, 2.54 \mathrm{~g}, 3.18 \mathrm{~g}, 4.77 \mathrm{~g}$, and $6.36 \mathrm{~g}$ ) were slowly added. A volume of $200 \mathrm{~mL}$ of deionized water was added into the solution, with stirring for another 2 hours. The resultant solution was placed in a $60^{\circ} \mathrm{C}$ water bath and aged for 24 hours to yield hydroxyl-Fe pillaring solutions with $\mathrm{OH} / \mathrm{Fe}$ molar ratios of $0.2,0.4,0.6,0.8,1.0(1 \mathrm{OH} / \mathrm{Fe}$ pillaring solution), 1.5, and 2.0, respectively. The hydroxyl-Fe pillaring solutions were slowly added into a suspension of Mont (prepared by adding $6 \mathrm{~g}$ of Mont to $100 \mathrm{~mL}$ of deionized water) under stirring. The mixtures were allowed to react with constant stirring for 2 hours and then were aged at $60^{\circ} \mathrm{C}$ water bath. The resultant mixtures were then repeatedly centrifuged and rinsed with deionized water. The resulting powders were dried at $105^{\circ} \mathrm{C}$ for 2 hours, milled through a 200-mesh sieve, and then dried again at $105^{\circ} \mathrm{C}$ for another 2 hours. Finally, the $\mathrm{OH} /$ Fe-Mont adsorbents with different molar ratios were obtained and denoted as $0.2 \mathrm{OH} / \mathrm{Fe}-\mathrm{Mont}, 0.4 \mathrm{OH} /$ Fe-Mont, 0.6OH/Fe-Mont, $0.8 \mathrm{OH} / \mathrm{Fe}-$ Mont, $1 \mathrm{OH} /$
Fe-Mont, 1.5OH/Fe-Mont, and 2OH/Fe-Mont $[10,20-22]$, respectively.

(2) Fe/Al-composite-pillared Mont adsorbents were prepared as follows: $60 \mathrm{~mL}$ of a solution of $\mathrm{Na}_{2} \mathrm{CO}_{3}$ $(1.0 \mathrm{~mol} / \mathrm{L})$ was slowly trickled into $100 \mathrm{~mL}$ of $\mathrm{AlCl}_{3}$ solution $(0.5 \mathrm{~mol} / \mathrm{L})$ at $80^{\circ} \mathrm{C}$ with constant stirring. The solution was then diluted to $200 \mathrm{~mL}$ with deionized water and allowed to stir for 2 hours. The resultant solution was then aged in a $60^{\circ} \mathrm{C}$ water bath for 48 hours to yield a hydroxyl-Al pillaring reagent with an $\mathrm{OH} / \mathrm{Al}$ molar ratio of 2.4 , henceforth referred to as $2.4 \mathrm{OH} / \mathrm{Al}$ pillaring solution. Various amounts of $2.4 \mathrm{OH} / \mathrm{Al}$ pillaring solution (200.0 mL, $195.9 \mathrm{~mL}, 192.0 \mathrm{~mL}, 184.6 \mathrm{~mL}, 165.5 \mathrm{~mL}$, $141.2 \mathrm{~mL}, 109.1 \mathrm{~mL}, 88.9 \mathrm{~mL}$, and $75.0 \mathrm{~mL}$ ) and the respective volumes of $1 \mathrm{OH} / \mathrm{Fe}$ pillaring solution required to attain a final volume of $200 \mathrm{~mL}(0 \mathrm{~mL}$, $4.1 \mathrm{~mL}, 8.0 \mathrm{~mL}, 15.4 \mathrm{~mL}, 34.5 \mathrm{~mL}, 58.8 \mathrm{~mL}, 90.9 \mathrm{~mL}$, $111.1 \mathrm{~mL}$, and $125.0 \mathrm{~mL}$ ) were added with constant stirring to a suspension of Mont at $60^{\circ} \mathrm{C}$ (prepared by adding $6 \mathrm{~g}$ of Mont to $100 \mathrm{~mL}$ of deionized water). The resultant mixture was then allowed to stir for a further 2 hours and aged in a $60^{\circ} \mathrm{C}$ water bath. The aged mixtures were then repeatedly centrifuged and rinsed with deionized water to remove excess ions; this process yielded different molar ratios of Fe/Al-Mont. The resulting powder was dried at $105^{\circ} \mathrm{C}$ for 2 hours, milled through a 200 mesh sieve, and then dried again at $105^{\circ} \mathrm{C}$ for another 2 hours. This procedure yielded samples of Fe/ Al-Mont adsorbents of varying molar ratios, denoted as $\mathrm{OH} / \mathrm{Al}-\mathrm{Mont}$, 0.025Fe/Al-Mont, 0.05Fe/ Al-Mont, 0.1Fe/Al-Mont, 0.25Fe/Al-Mont, 0.5Fe/ Al-Mont, $1 \mathrm{Fe} / \mathrm{Al}-\mathrm{Mont}$, 1.5Fe/Al-Mont, and $2 \mathrm{Fe} /$ Al-Mont $t$ [10, 20-22].

2.3. Adsorbent Characterization. Powder X-ray diffraction (XRD) was performed to investigate the crystal structure of the samples on a Rigaku MiniFlex 600 X-ray diffractometer with Ni-filtered $\mathrm{Cu} \mathrm{K} \alpha$ irradiation $(\alpha=1.5406 \AA)$. And data were recorded at a scan rate of $0.8 \mathrm{sec} / \mathrm{step}$ in the range from $5^{\circ}$ to $20^{\circ}$. Fourier transform infrared (FT-IR) spectra of the samples were recorded on a Thermo Scientific Nicolet iS10 spectrometer by using $\mathrm{KBr}$ pellets. The scanning electron microscope (SEM) images were taken through a SUPRA 55 instrument (Zeiss Sigma). Specific surface area analysis (BET) is the use of N2 low-temperature adsorption and desorption to determine the specific surface area, pore volume, and pore size distribution of the sample; the sample is prebaked at $90^{\circ} \mathrm{C}$ and then degassed at $150^{\circ} \mathrm{C}$ for 4 hours for analysis. X-ray photoelectron spectroscopy (XPS) is the use of X-ray photoelectron spectroscopy to qualitatively analyze the element types of substances (instrument performance parameters: aluminum target (photoelectron energy $\mathrm{hv}=1486.6 \mathrm{eV}$ ), energy resolution $0.6 \mathrm{eV}$, and spatial resolution $<3 \mathrm{um}$ ), collect the full scan spectrum of $2-1202 \mathrm{eV}$ of the sample, and collect the narrow scan spectrum of the relevant orbits of each element. Thermal 
analysis research (TG-DSC) is to use the thermal analysis system-synchronous thermal analyzer to study the phase transition and reaction enthalpy of the sample and to determine its characteristic parameters. The test method is to put the sample in still air, set the program heating rate to $10^{\circ} \mathrm{C} / \mathrm{min}$, and measure the temperature range from room temperature to $1000^{\circ} \mathrm{C}$.

2.4. ZEA Adsorption Test. $0.100 \mathrm{~g}$ of Mont and modified Mont adsorbent was used; the solution volume was $20.0 \mathrm{~mL}$; samples were wrapped in aluminium foil to prevent exposure to light and placed in a temperature-controlled oscillator set to $170 \mathrm{rpm}$. The samples were then centrifuged at $4000 \mathrm{rpm}$ for 5 minutes, and the amount of ZEA remaining in solution was analysed via HPLC (Agilent 1260 HPLC). The ZEA calibration curve was established using 9 standards with a linear correlation coefficient of $r^{2}>0.999$. The equilibrium adsorption experiments were conducted with a fixed oscillator time of 24 hours and a temperature of $37^{\circ} \mathrm{C}$. In the adsorption isotherm studies, $20 \mathrm{~mL}$ of ZEA solution at various concentrations $(0.1,0.25,0.5,1,2.5$, and $5 \mathrm{mg} / \mathrm{L})$ was added to different adsorbents at $25^{\circ} \mathrm{C}$. The effects of solution $\mathrm{pH}(2,4,6,8,10)$ at $25^{\circ} \mathrm{C}$ and temperature $(15,25,35,45$, $55^{\circ} \mathrm{C}$ ) on the adsorption characteristics were investigated with various adsorbents. Adsorption kinetics studies were conducted by first adding various adsorbents to $20 \mathrm{~mL}$ of ZEA $\left(5 \mathrm{mg} / \mathrm{L}, \mathrm{pH} 8,25^{\circ} \mathrm{C}\right)$, and then aliquots were taken after centrifugation at time intervals of $0.25,0.5,0.75,1,2,4,8,12$, and 24 hours to determine the ZEA concentration.

\section{Results and Discussion}

3.1. SEM Analysis. The SEM images of the original montmorillonite and pillared montmorillonite before and after adsorbing ZEA are shown in Figure 1. It can be seen that the pore structure of montmorillonite changes to a certain extent after adsorption. Among them, K10-Mont adsorbs ZEA, the larger pores are more blocked, the mesopores are less, and the surface fine particles are increased. The pores of $1.5 \mathrm{OH} / \mathrm{Fe}-\mathrm{Mont}$ samples are filled with a certain amount of flocs, the pore size becomes smaller, and the flocs on the clay surface decrease after adsorption, and the macropore density decreases. The smaller floc particles on the surface are reduced, thereby making the surface of montmorillonite smoother. After adsorption of ZEA on $0.5 \mathrm{Fe} / \mathrm{Al}-\mathrm{Mont}$ samples, the density of the larger pore diameter decreases, the macropores are blocked, and the spherical particles on the surface increase, indicating that the ZEA molecules enter the mineral interlayer domain.

3.2. BET Analysis. It can be seen from Table 1 that the specific surface area of $\mathrm{OH} / \mathrm{Fe}-\mathrm{Mont}$ is greater than K10Mont, but the total pore volume and pore size are less than K10-Mont. The specific surface area of OH/Al-Mont and hydroxyl-aluminum-doped hydroxyiron-aluminum pillared montmorillonite $(\mathrm{Fe} / \mathrm{Al} \leq 0.5)$ is less than $\mathrm{K} 10$-Mont, and the total pore volume and pore size are also less than K10-Mont. The maximum BET specific surface area of $1.5 \mathrm{OH} / \mathrm{Fe}-\mathrm{Mont}$ reaches $271.9 \mathrm{~m}^{2} / \mathrm{g}$ and the pore volume reaches $0.347 \mathrm{~cm}^{3} / \mathrm{g}$, but the pore size is smaller at $5.11 \mathrm{~nm}$.

Figure 2 shows the isotherms of nitrogen adsorption and desorption of hydroxyiron-pillared montmorillonite and the isotherms of nitrogen adsorption and desorption of hydroxyiron-aluminum-pillared montmorillonite, respectively. It can be seen from Figure 2 that the adsorption isotherms of pillared montmorillonite are relatively close in shape, similar to the type II adsorption isotherms in the BDDT classification, and are typical of porous media adsorption. When the relative pressure is between 0.05 and 0.45 , the adsorption amount increases gently, indicating that the pore size of montmorillonite is continuously distributed. When the relative pressure is greater than 0.45 , the amount of adsorption increases rapidly, and the adsorption isotherm warps, which is caused by capillary condensation in the larger pores [23].

Desorption branch of the low-temperature nitrogen adsorption isotherm of the sample is processed, and the pore volume distribution result of the obtained sample is shown in Figure 3. The most probable pore diameters of K10-Mont and $\mathrm{OH} / \mathrm{Fe}-\mathrm{Mont}$ are all around $3.6 \mathrm{~nm}$, and both belong to the mesopore range (mesopores). The pore volume of $\mathrm{OH} /$ Fe-Mont is improved compared to K10-Mont, but it is not obvious, and the maximum pore volume can be increased by $50 \%(1.5 \mathrm{OH} / \mathrm{Fe}-\mathrm{Mont})$, so this study believes that the pillaring agent $\mathrm{OH} / \mathrm{Fe}$ effect is to increase the number of mesopores, which has a significant effect on the increase in pore volume. The OH/Al-Mont's most achievable pore diameter is $3.609 \mathrm{~nm}$, and its most achievable pore volume is $0.0264 \mathrm{~cm}^{3} / \mathrm{g}$. Compared with $\mathrm{K} 10-$ Mont, the most achievable pore volume is significantly improved. After the $\mathrm{OH} / \mathrm{Fe}$ pillaring agent is added to the $\mathrm{OH} / \mathrm{Al}$ pillaring agent, when the Fe/ Al molar ratio is 0.5 , the most permissible pore volume is $0.0222 \mathrm{~cm}^{3} / \mathrm{g}$.

3.3. TGA Analysis. Figure 4 is a TG-DSC chart of K10-Mont, $\mathrm{OH} / \mathrm{Fe}-\mathrm{Mont}, \mathrm{Fe} / \mathrm{Al}-\mathrm{Mont}$, and $\mathrm{OH} / \mathrm{Al}-\mathrm{Mont}$. These four samples have similar TG curves. When the temperature of $\mathrm{K} 10$-Mont reaches $60^{\circ} \mathrm{C}$, a large endothermic valley begins to appear on the DSC curve, and the thermogravimetric curve drops rapidly in this interval. Because the K10-Mont absorbs heat, a large amount of attached water and interlayer water escape. When the temperature reaches above $600^{\circ} \mathrm{C}$, a broad endothermic valley appears on the DSC curve. When the temperature is around $650^{\circ} \mathrm{C}$, the $\mathrm{K} 10$-Mont dehydroxylation endotherm will produce an endothermic valley. When the temperature continues to rise above $800^{\circ} \mathrm{C}$, the montmorillonite lattice will be destroyed, showing an amorphous body, and there will also be absorption hot valley. There is no obvious temperature division between these two processes, which will cause the endothermic valleys to overlap, so a wide endothermic valley is formed. When montmorillonite is introduced into hydroxyiron and hydroxyaluminum pillaring agent, the thermal stability is enhanced, and the thermal stability of hydroxyiron pillared montmorillonite is better than that of hydroxyl-aluminum pillared montmorillonite. 


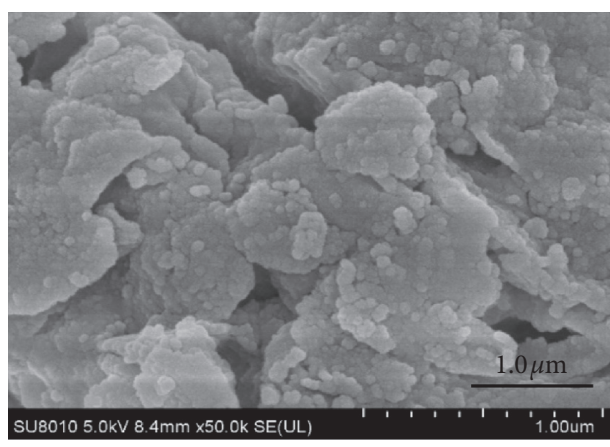

(a)

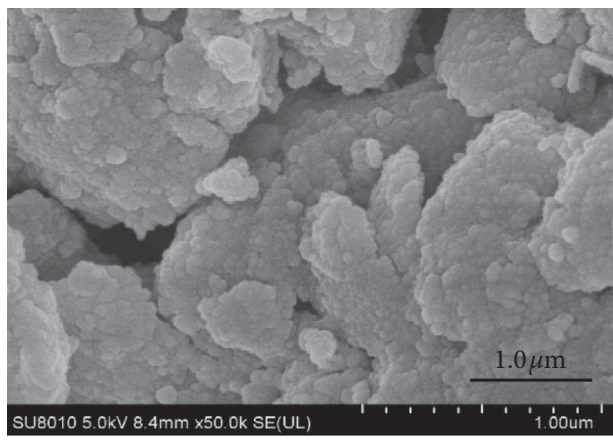

(c)

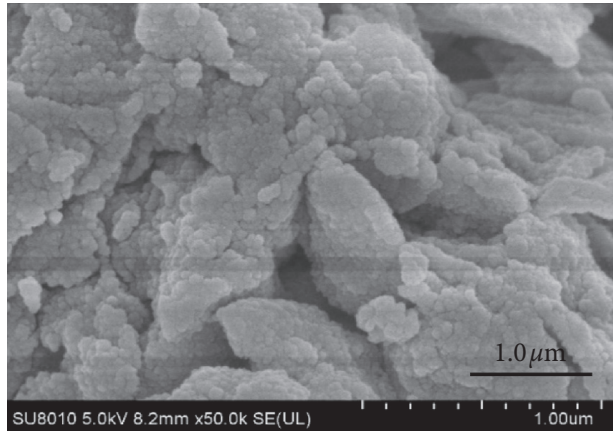

(e)

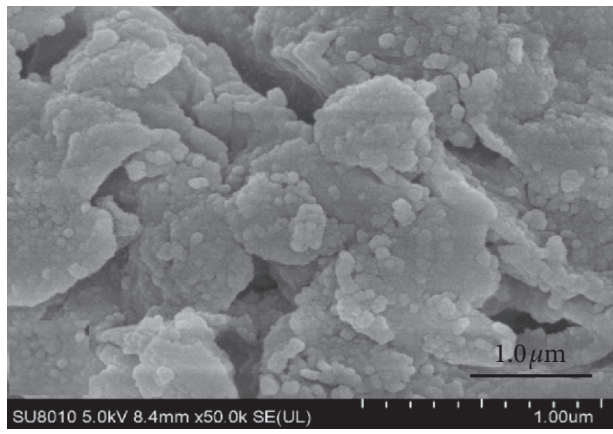

(g)

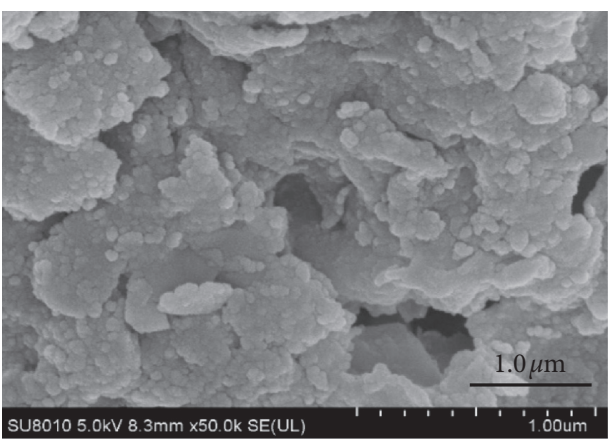

(b)

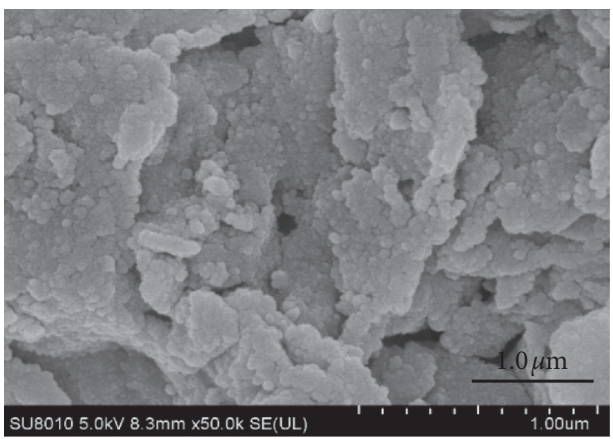

(d)

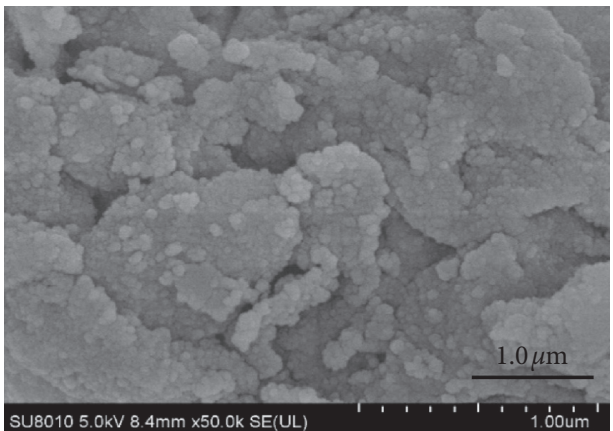

(f)

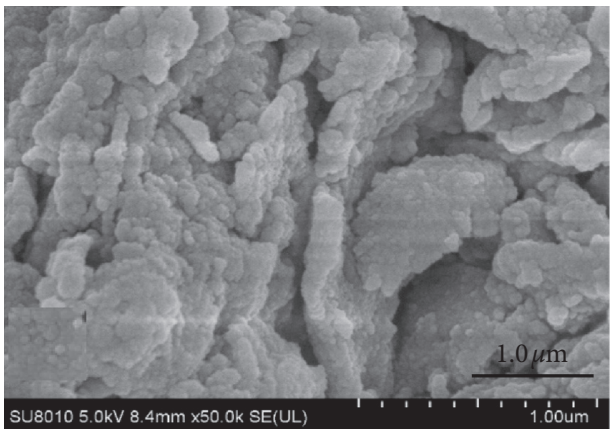

(h)

Figure 1: SEM images of K10-Mont (a, b), 1.5 OH/Fe-Mont (c, d), $0.5 \mathrm{Fe} / \mathrm{Al}$-Mont (e, f), and OH/Fe-Mont (g, h) before and after adsorption of ZEA.

3.4. XPS Analysis. The XPS spectrum of the original montmorillonite and pillared montmorillonite before and after the adsorption of ZEA is shown in Figure 5, and the partial element spectrum is shown in Figures 6 and 7. It can be seen from the full spectrum of the three montmorillonites
(K10-Mont, $1.5 \mathrm{OH} / \mathrm{Fe}-\mathrm{Mont}, 0.5 \mathrm{Fe} / \mathrm{Al}-\mathrm{Mont}$ ) that the $\mathrm{Fe}$ signal of the original montmorillonite K10-Mont is very weak. After aluminum struts, the signal of Fe characteristic peak is obviously enhanced, indicating that the Fe content near the surface increases. After the adsorption of ZEA, the 
TABLE 1: Surface area: pore volume and pore size of montmorillonites.

\begin{tabular}{lccc}
\hline Sampel & BET surface area $\left(\mathrm{m}^{2} / \mathrm{g}\right)$ & Total pore volume $\left(\mathrm{cm}^{3} / \mathrm{g}\right)$ & Pore size $(\mathrm{nm})$ \\
\hline K10-Mont & 237.5 & 0.376 & 6.33 \\
1.5 OH/Fe-Mont & 271.9 & 0.347 & 5.11 \\
OH/Al-Mont & 194.4 & 0.303 & 6.23 \\
0.5 Fe/Al-Mont & 177.2 & 0.324 & 7.32 \\
\hline
\end{tabular}

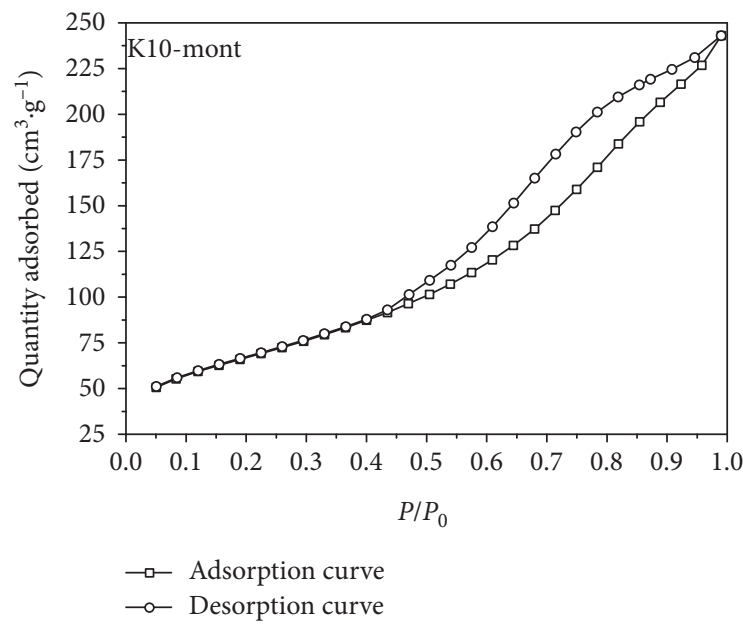

(a)

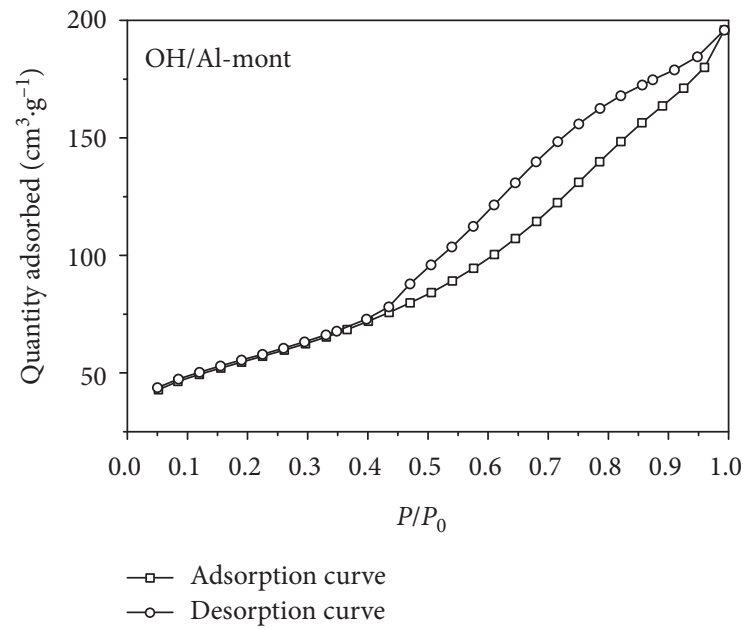

(c)

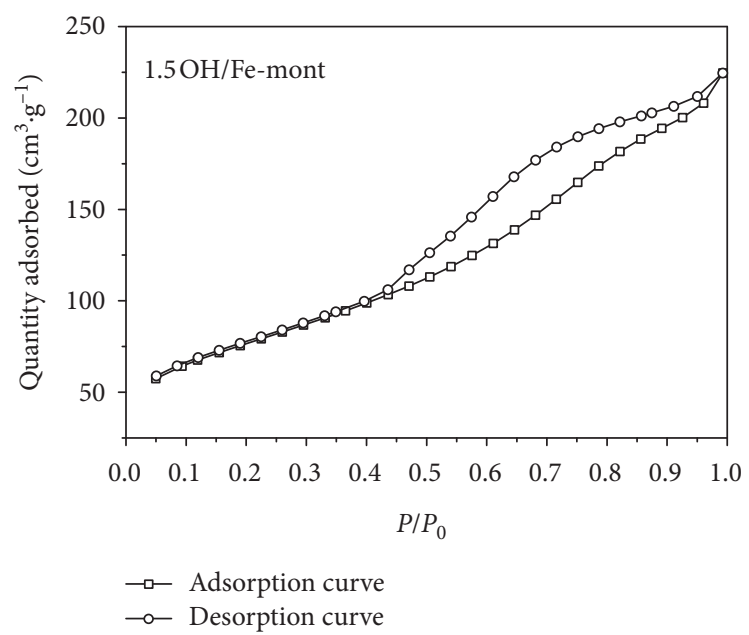

(b)

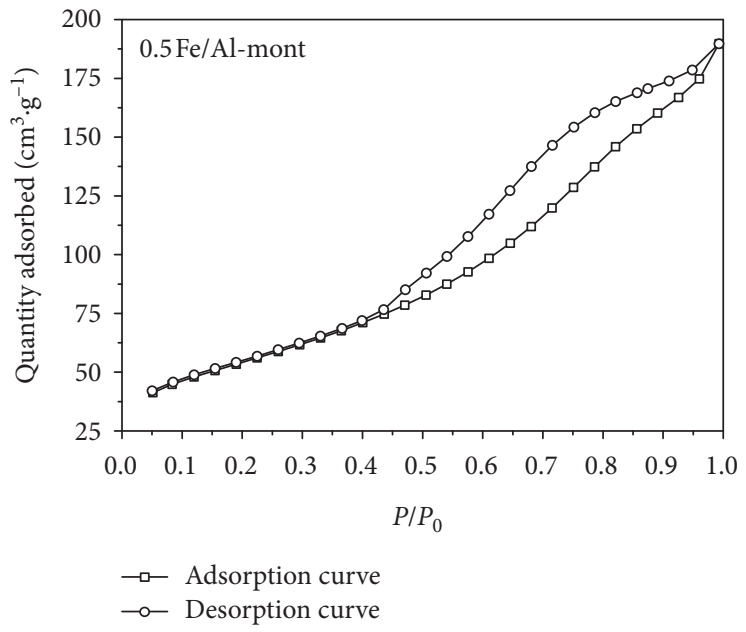

(d)

FIGURE 2: Nitrogen adsorption-desorption isotherm of hydroxyl-Fe-Al-pillared montmorillonites.

Fe content decreased again, indicating that after ZEA was adsorbed to the pillared montmorillonite, Fe was replaced, which is consistent with the XRD and FTIR results. To further study the adsorption mechanism of iron and ironaluminum pillared montmorillonite, the characteristic elements of the two pillared montmorillonite were analysed in detail. Figure 6 shows the changes of the binding energies of $\mathrm{O} 1 \mathrm{~s}, \mathrm{Al} 2 \mathrm{p}, \mathrm{Si} 2 \mathrm{p}$, and Fe $2 \mathrm{p}$ before and after adsorption of ZEA by hydroxyiron pillared montmorillonite. It can be seen from Figure 7 (a) that after the adsorption of $\mathrm{ZEA}, \mathrm{Fe}$ is replaced by ion exchange, the content decreases sharply, and the binding energy rises from $712.23 \mathrm{eV}$ to $712.74 \mathrm{eV}$.
Therefore, Fe participates in the adsorption of ZEA as a lost electron.

Figure 7 shows the inner layer of oxygen 1s electrons (O1s), the inner layer of aluminum $2 p$ electrons (Al2p), the inner layer of silicon $2 p$ electrons (Si2p), and iron XPS spectrum of layer $2 \mathrm{p}$ electrons $(\mathrm{Fe} 2 \mathrm{p})$. It can be seen from Figure 7 (a) that after the adsorption of ZEA by $0.5 \mathrm{Fe} / \mathrm{Al}$ Mont, the binding energy of Fe $2 \mathrm{p}$ rises from $712.2 \mathrm{eV}$ to $712.74 \mathrm{eV}$, and iron as the electron loss party participates in the adsorption of ZEA, but the content does not change much. OH/Fe-Mont and Fe/Al-Mont have different mechanisms for ZEA adsorption. The Fe2p and O1s of 


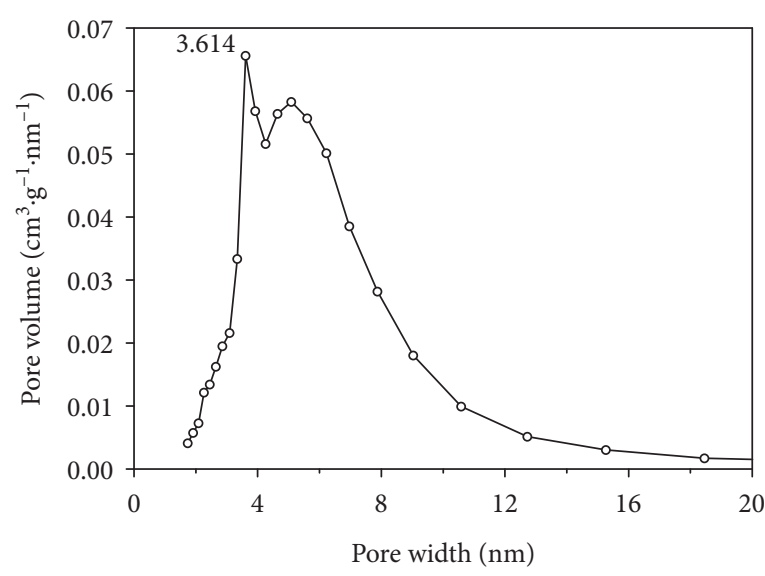

$\multimap$ K10-mont

(a)

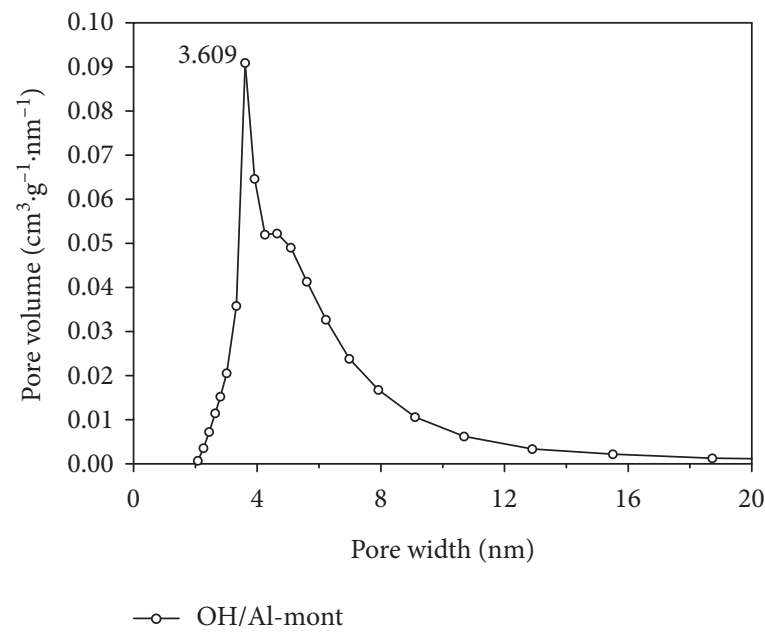

(c)

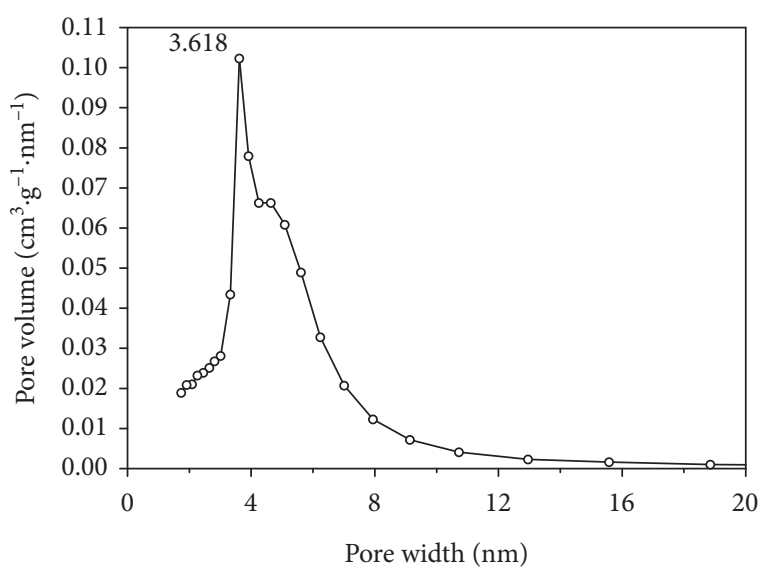

$\multimap 1.5 \mathrm{OH} / \mathrm{Fe}-\mathrm{mont}$

(b)

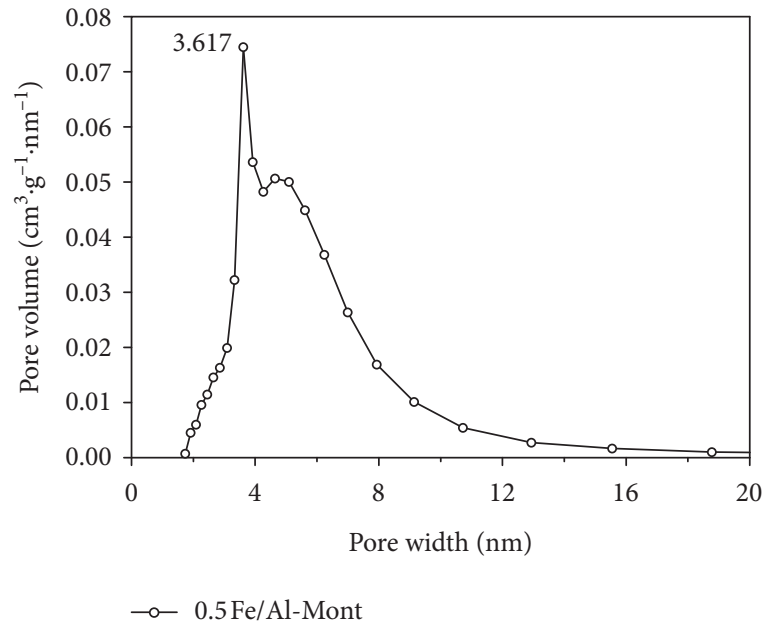

(d)

Figure 3: Pore volume distribution of hydroxyl-Fe-pillared montmorillonites.

hydroxyiron-pillared montmorillonite contributed greatly to the negative charge movement on the surface of montmorillonite during the adsorption process, while the ironhydroxyaluminum pillared montmorillonite contributed the most to iron. Most of the iron in the former is removed from montmorillonite, while the latter has limited O1s contribution. The difference in adsorption mechanism leads to a difference in the amount of ZEA adsorption.

3.5. XRD Analysis. Both the XRD patterns and interlayer distances $\mathrm{d}(001)$ of $\mathrm{OH} / \mathrm{Fe}-\mathrm{Mont}, \mathrm{OH} / \mathrm{Al}-\mathrm{Mont}$, and $\mathrm{Fe} / \mathrm{Al}$ Mont are shown in Figure 8. It can be observed from the XRD patterns that while modified and unmodified Mont exhibit similar characteristic XRD peaks, characteristics of coexposed (001) facets peak such as the $2 \theta$, peak full width at half maximum, and diffraction peak intensity changed significantly. This result indicates that the hydroxyl pillar modification process significantly altered the overall structure of Mont, resulting in a significant change in the $\mathrm{d}(001)$ of both $\mathrm{OH} / \mathrm{Fe}-$ Mont and Fe/Al-Mont.
As illustrated in Figure $8(\mathrm{a})$, the $\mathrm{d}(001)$ of Mont is $1.19 \mathrm{~nm}$, whereas the adsorbent $0.6 \mathrm{OH} / \mathrm{Fe}-$ Mont exhibited a maximum $\mathrm{d}(001)$ of $1.62 \mathrm{~nm}$. This increase in interlayer distance was observed to occur in two stages: the $\mathrm{d}(001)$ increased gradually when the $\mathrm{OH} / \mathrm{Fe}$ molar ratio was less than 0.8 ; however, once the $\mathrm{OH} / \mathrm{Fe}$ molar ratio exceeded 0.8 , the $\mathrm{d}(001)$ was observed to increase rapidly until it reached a maximum of $1.62 \mathrm{~nm}$ at an $\mathrm{OH} / \mathrm{Fe}$ molar ratio of 1.5. This result indicates that the primary hydrolysate of Fe ions had partially intercalated into the Mont particle layer, resulting in an increase in interlayer distance. When the $\mathrm{OH} / \mathrm{Fe}$ molar ratio was increased to 2 , the $\mathrm{d}(001)$ was observed to decrease to $1.54 \mathrm{~nm}$. A rise in $\mathrm{pH}$ due to a large $\mathrm{OH} / \mathrm{Fe}$ molar ratio in solution led to the precipitation of Fe hydroxide, which covered much of the Mont surface and rendered the pillared structure ineffective. For all of the samples, none of the XRD patterns exhibited any pillared structures with a $\mathrm{d}(001)$ of $2.5 \mathrm{~nm} \pm 0.4 \mathrm{~nm}$, which has been reported in various publications. This observation agrees with the perspective of Diekman et al. [24], who hypothesized that unlike Al cations, which can form stable, consistent-sized structures (Keggin 


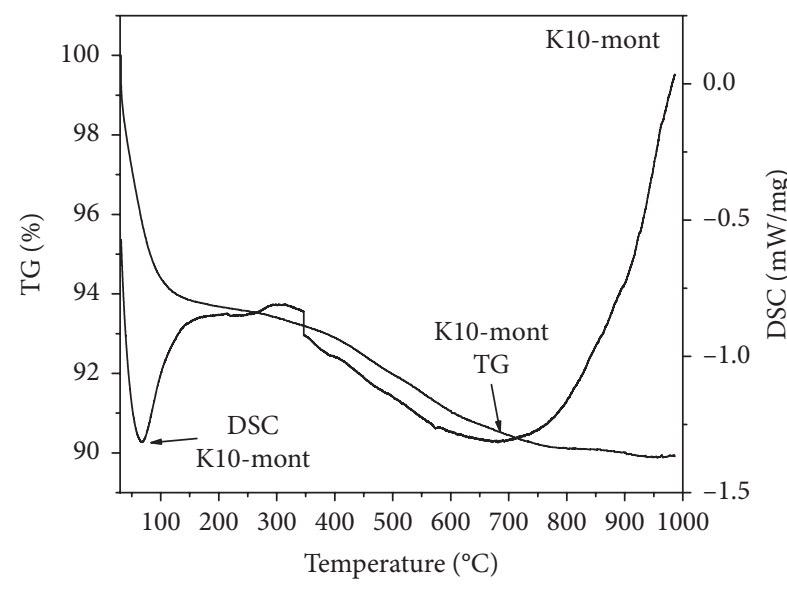

(a)

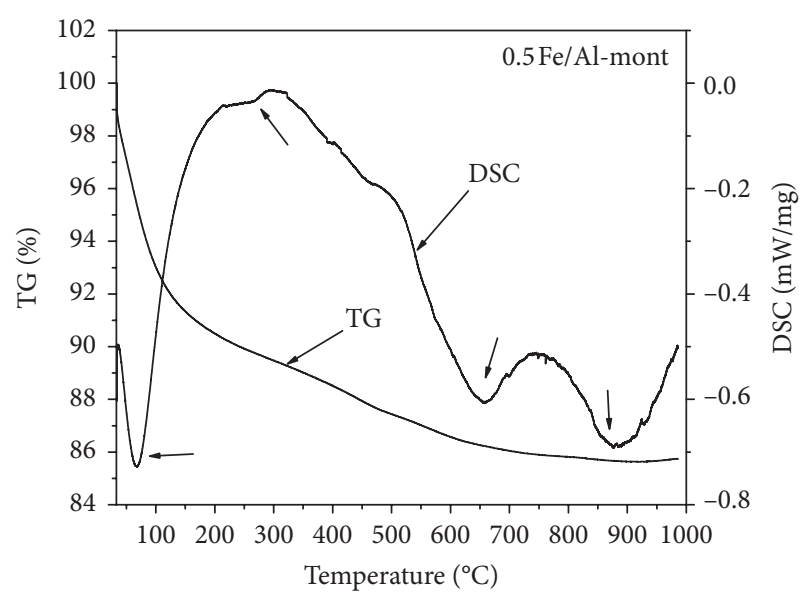

(c)

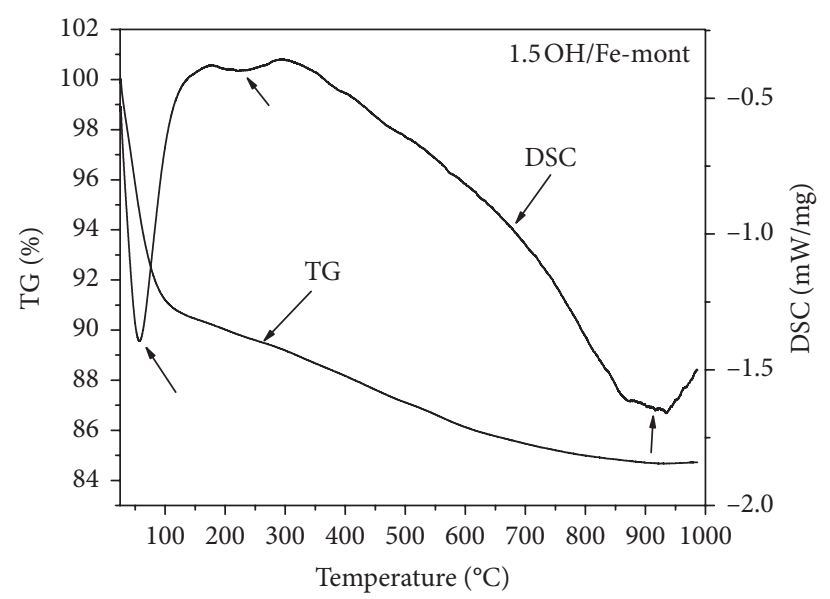

(b)

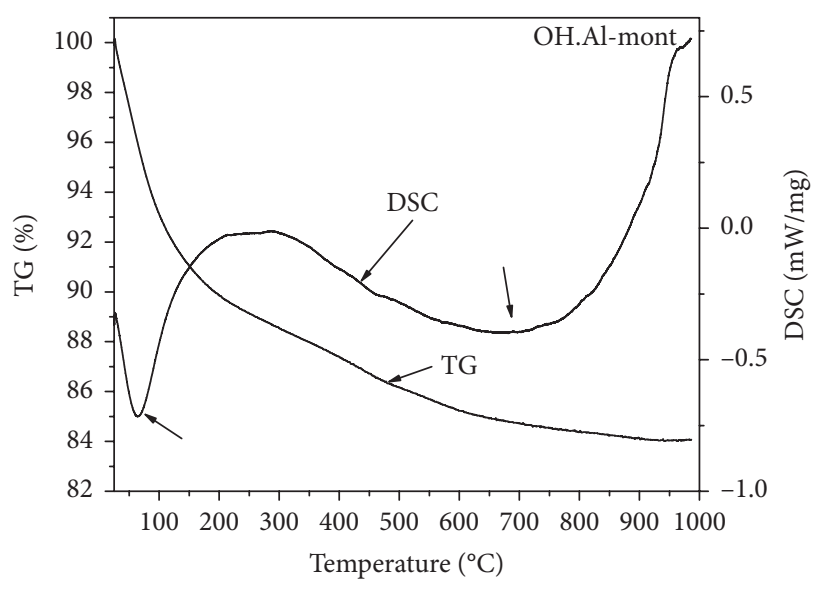

(d)

Figure 4: TG-DSC of pillared montmorillonite.

structure) after hydrolysis, the hydrolysates of Fe cations vary in size and consistency, rendering the formation of pillared structures difficult.

Figure 8(b) indicates that X-ray diffraction patterns basic of hydroxyl-Fe-Al-pillared remained consistent with hydroxyl-Al-pillared montmorillonite when $\mathrm{Fe} / \mathrm{Al} \leq 0.05$, the $\mathrm{d}(001)$ value of Fe/Al-Mont slightly are higher than the hydroxyl-Al free hydroxyl. This is due to the ion radius of $\mathrm{Fe}^{3+}(0.064 \mathrm{~nm})>\mathrm{Al}^{3+}(0.051 \mathrm{~nm})$, causing $\mathrm{d}(001)$ slightly larger, but the $\mathrm{d}(001)$ remained consistent at approximately $1.74 \mathrm{~nm} \pm 0.1 \mathrm{~nm}$, which does not agree with the range of $2.3 \mathrm{~nm} \pm 0.1 \mathrm{~nm}$ reported in the literature [25]. This discrepancy may be attributed to inconsistencies in the pillar structure resulting from differences in experimental conditions. The $\mathrm{d}(001)$ was observed to decrease from 1.70 to $1.55 \mathrm{~nm}$ when the $\mathrm{Fe} / \mathrm{Al} \geq 0.10$, which indicates that the interlayer spacing no longer exhibits the Keggin structure. This observation can be attributed to the fact that the addition of $\mathrm{Fe}$ destroys the $\mathrm{OH} / \mathrm{Al}$-Mont structure, forming a composite material that consists of polymeric $\mathrm{Fe}^{3+}$ structures. This structural change is reflected in the change in interlayer spacing, and with an increasing rate of $\mathrm{Fe}$, the pillared Mont structure becomes dominated by $\mathrm{OH} / \mathrm{Fe}$, thus reducing the interlayer spacing.

3.6. FT-IR Analysis. The FTIR spectra and analysis results of Mont, $1.5 \mathrm{OH} / \mathrm{Fe}-\mathrm{Mont}$, OH/Al-Mont, and 0.5Fe/Al-Mont before and after ZEA adsorption are depicted in Figure 9. Figure 9 indicates that hydroxyl-Fe-Al-pillared Mont exhibited a vibration peak at $1384 \mathrm{~cm}^{-1}$ prior to ZEA adsorption, which suggests the presence of $\mathrm{NO}_{3}^{-}$ions despite repeated centrifugation/washing cycles. With the increase of the content of the iron in the montmorillonite, the needed charge to balance the positive is also increased, which means that the number of $\mathrm{NO}_{3}^{-}$entering the montmorillonite was increased. The $\mathrm{NO}_{3}^{-}$concentration in the solution of after the column is lower than that of before the column $(37.2 \mathrm{mg} / \mathrm{l})$, which is verified by the $\mathrm{NO}_{3}^{-}$ion as counter-ions to the positively charged Fe hydrolysate polymers that were located outside of the Mont interlayers. This result shows that much of the iron hydrolysate polymer did not enter the Mont interlayer through ion exchange. The presence of $\mathrm{NO}_{3}^{-}$ions thus bestows an anionic exchange functionality upon 


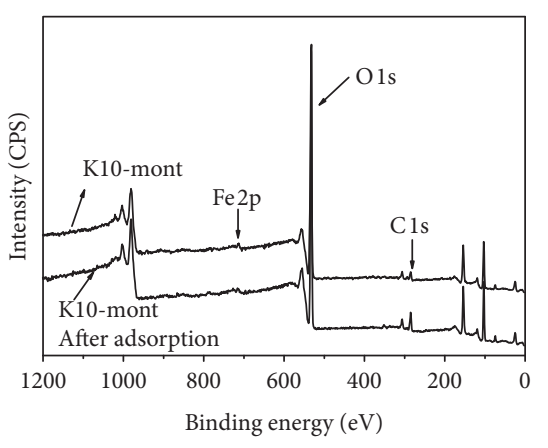

(a)

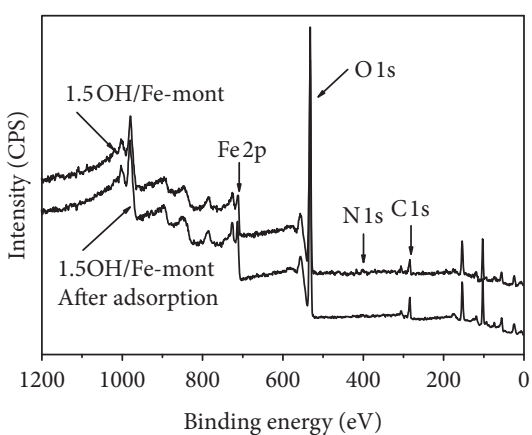

(b)

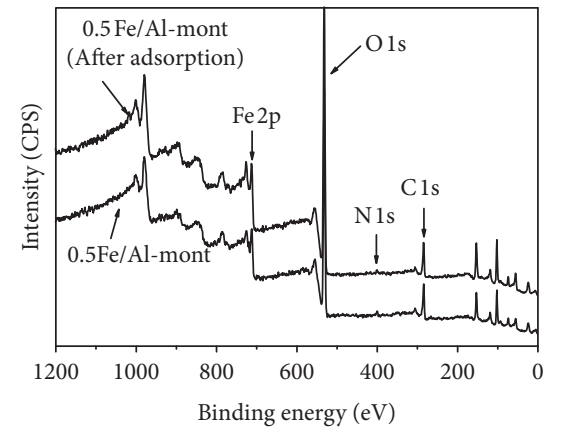

(c)

FIGURE 5: X-ray photoelectron spectra of pillared montmorillonites.

hydroxyl-pillared Mont, allowing anions to enter Mont to give rise to new functionalities. Research by Akin and Zeng has also confirmed this conclusion $[25,26]$. The vibrational peak at $1384 \mathrm{~cm}^{-1}$ in $\mathrm{OH} / \mathrm{Al}-\mathrm{Mont}$ was comparatively weak, which indicates that only a small amount of $\mathrm{NO}_{3}^{-}$ion is present. This result occurs mainly because hydroxyl-Al ions enter the Mont spacing through ion exchange, and $\mathrm{NO}_{3}^{-}$ions escaped the Mont interlayers during this process [24]. The same $1384 \mathrm{~cm}^{-1}$ absorption peak was observed to weaken significantly and even disappear after the ZEA adsorption assays, which suggests that $\mathrm{NO}_{3}^{-}$ions escaped the Mont interlayers by exchanging with the relevant ion of $\mathrm{ZEA}$, confirming that ion exchange is the dominant mechanism of ZEA adsorption onto Mont adsorbents [27].

3.7. Effects of $\mathrm{OH} / \mathrm{Fe}, \mathrm{OH} / \mathrm{Al}$, and $\mathrm{Fe} / \mathrm{Al}$ Molar Ratios. Figure 10 presents the equilibrium adsorption capacities of pristine Mont and modified Mont with differing $\mathrm{OH} / \mathrm{Fe}$ and $\mathrm{Fe} / \mathrm{Al}$ molar ratios assayed after 24 hours of adsorption. It can be observed from this analysis that pristine Mont (with an $\mathrm{OH} / \mathrm{Fe}$ molar ratio of 0 ) exhibited an equilibrium adsorption capacity of $0.05 \mathrm{mg} / \mathrm{g}$, whereas the adsorption capacity of $\mathrm{OH} / \mathrm{Fe}-$ Mont increased with increasing $\mathrm{OH} / \mathrm{Fe}$ molar ratios up to $<1.5$, reaching a maximum $\mathrm{ZEA}$ adsorption capacity of $0.28 \mathrm{mg} / \mathrm{g}$ when the $\mathrm{OH} / \mathrm{Fe}$ molar ratio was at 1.5. At this molar ratio, there was a 5 -fold increase in the adsorption capacity compared to pristine Mont. At $\mathrm{OH} /$ Fe molar ratios $>1.5$, the adsorption capacity was observed to decline. The equilibrium adsorption capacity of hydroxyl$\mathrm{Al}$-pillared Mont (i.e., Fe/ $\mathrm{Al}$ molar ratio of 0 ) was measured to be $0.51 \mathrm{mg} / \mathrm{g}$, whereas the adsorption capacity of Fe/AlMont increased with increasing $\mathrm{Fe} / \mathrm{Al}$ molar ratios up to $<0.5$, reaching a maximum of $0.56 \mathrm{mg} / \mathrm{g}$ at a $\mathrm{Fe} / \mathrm{Al}$ molar ratio of 0.5 . This value is a 10 -fold increase in the adsorption capacity compared to pristine Mont and is only slightly higher than hydroxyl-modified Al-pillared Mont [28].

Changes in the $\mathrm{d}(001)$ of pillared Mont as measured using XRD can be used to explain the impact of the $\mathrm{OH} /$ Fe molar ratio on the ZEA adsorption capacity. The adsorption capacity was observed to correlate with the $\mathrm{d}(001)$ of Mont: the maximum observed ZEA adsorption capacity coincided with the maximum $\mathrm{d}(001)$ value at an $\mathrm{OH} / \mathrm{Fe}$ molar ratio of 1.5 . This demonstrates that the $\mathrm{OH} /$ Fe pillar modification of Mont significantly improves the ZEA adsorption characteristics, up to a 5-fold increase in adsorption capacity. As indicated in Figure 4, compared with the adsorption to $\mathrm{OH} / \mathrm{Fe}-\mathrm{Mont}$, a different trend in the characteristics of ZEA adsorption to Fe/Al-Mont is observed, which is likely due to a complex mechanism associated with a composite-pillared structure that warrants further investigation. From the same Figure 4, it can also be observed that when the molar ratios of both $\mathrm{OH} / \mathrm{Fe}$ and $\mathrm{Fe} / \mathrm{Al}$ are less than 1.5, the ZEA adsorption capacities of $\mathrm{Fe} / \mathrm{Al}-\mathrm{Mont}$ and $\mathrm{OH} / \mathrm{Al}-\mathrm{Mont}$ are greater than those of $\mathrm{OH} / \mathrm{Fe}-\mathrm{Mont}$ and Mont. However, when the molar ratios of both $\mathrm{OH} / \mathrm{Fe}$ and $\mathrm{Fe} / \mathrm{Al}$ are $\geq 1.5$, the $\mathrm{ZEA}$ adsorption capacities of both $\mathrm{Fe} / \mathrm{Al}-\mathrm{Mont}$ and $\mathrm{OH} / \mathrm{Fe}-$ Mont are consistent. This result indicates that when the Fe content is low, both hydrolysed $\mathrm{Al}$ and hydrolysed FeAl-composite-pillared Mont are dominated by characteristics exhibited by hydrolysed $\mathrm{Al}$, leading to a relatively 


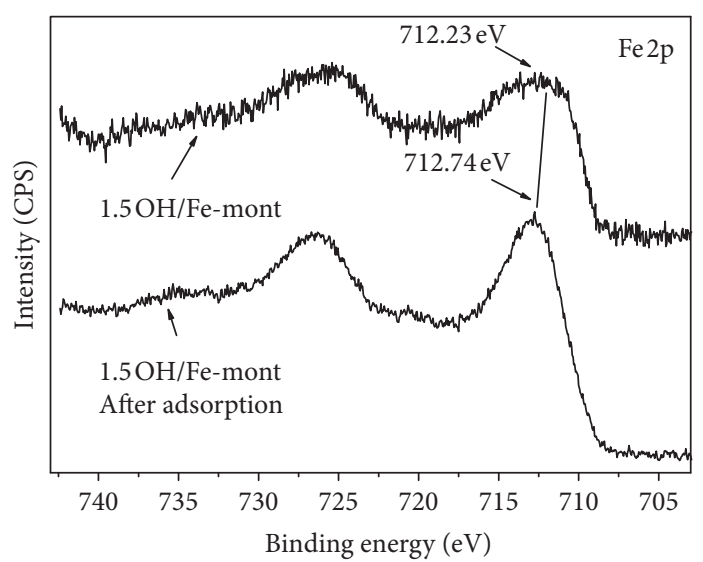

(a)

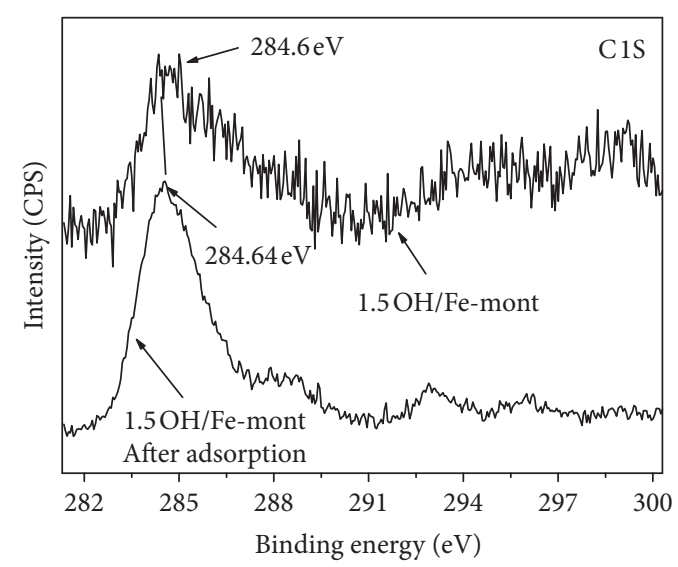

(c)

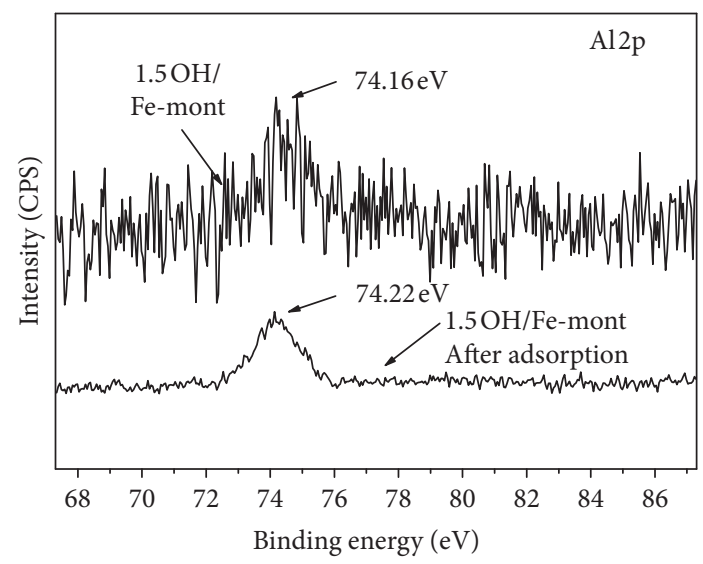

(e)

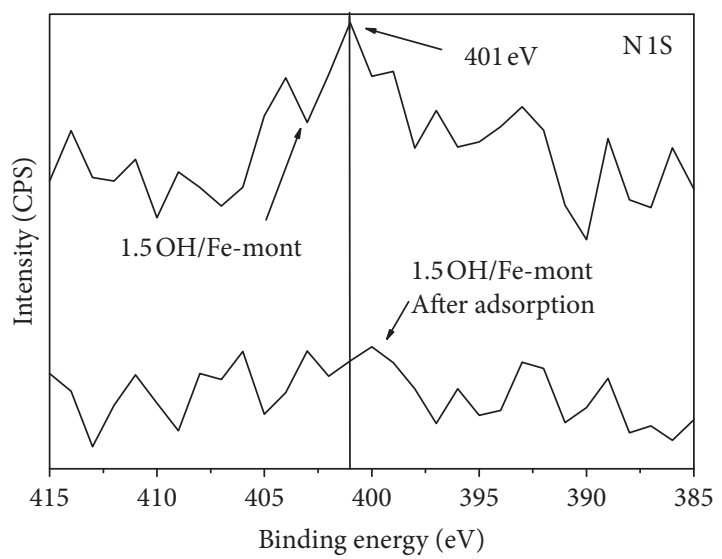

(b)

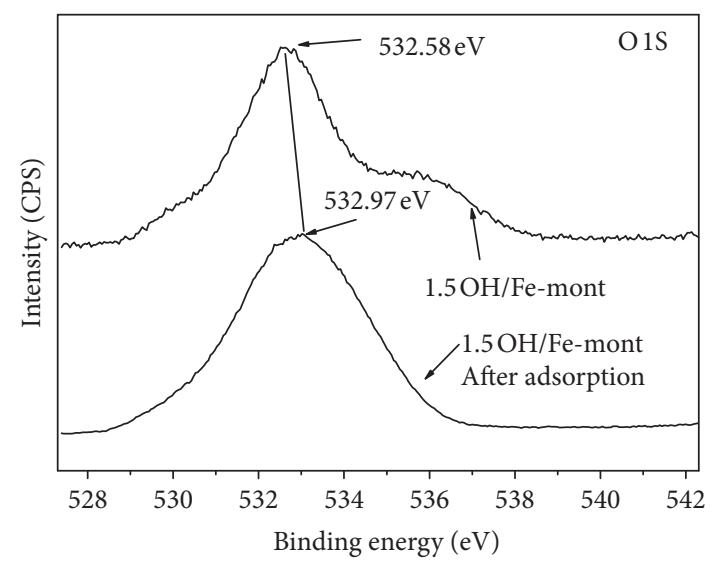

(d)

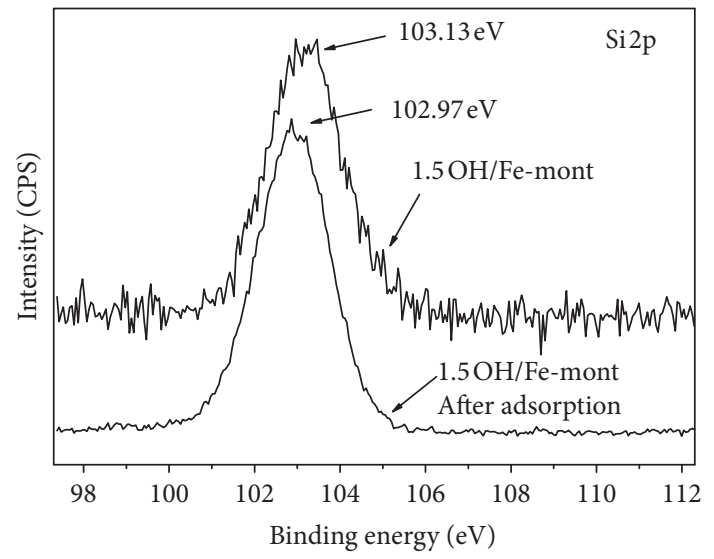

(f)

Figure 6: XPS of O1s, Al 2p, Si 2p, C1s, N1s and Fe 2p of 1.5OH/Fe-Mont.

stable Keggin structure and resulting in adsorption capacities greater than $\mathrm{OH} / \mathrm{Fe}-\mathrm{Mont}$. However, when the $\mathrm{Fe}$ content is high, the pillared Mont samples are dominated by characteristics exhibited by hydrolysed $\mathrm{Fe}$, wherein the pillared Mont structure is dependent on the coexistence of both pillars and lamellar layers; therefore, the ZEA adsorption capacities of both $\mathrm{Fe} / \mathrm{Al}-\mathrm{Mont}$ and $\mathrm{OH} / \mathrm{Fe}$ Mont are consistent [29-31].
3.8. Adsorption Isotherms. Figure 11 illustrates the effect of varying the initial ZEA concentration on the adsorption capacities of modified Mont. It can be observed that the ZEA adsorption capacities increased with increasing initial ZEA concentrations for Mont, 1.5OH/Fe-Mont, OH/Al-Mont, and $0.5 \mathrm{Fe} / \mathrm{Al}-\mathrm{Mont}$ adsorbents. This result occurs because at low ZEA concentrations, the number of ZEA molecules around an adsorption site is small, resulting in less 


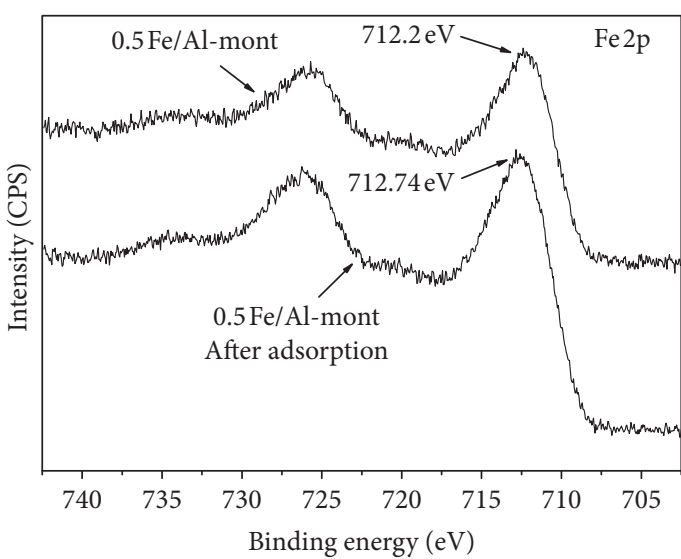

(a)

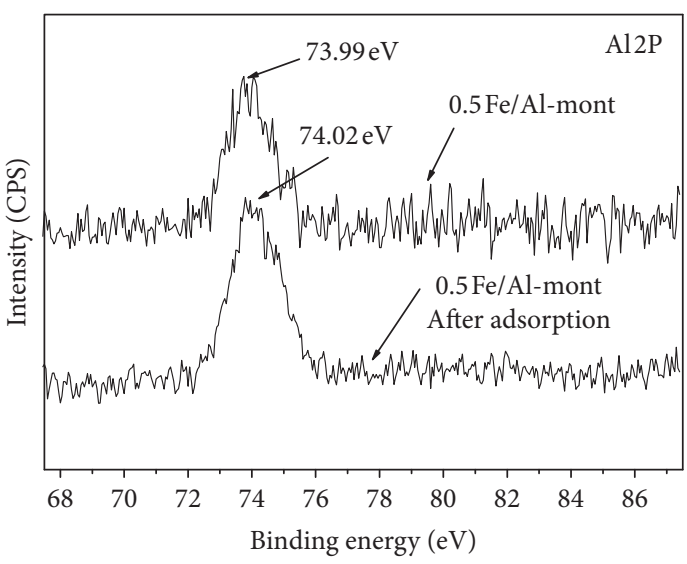

(c)

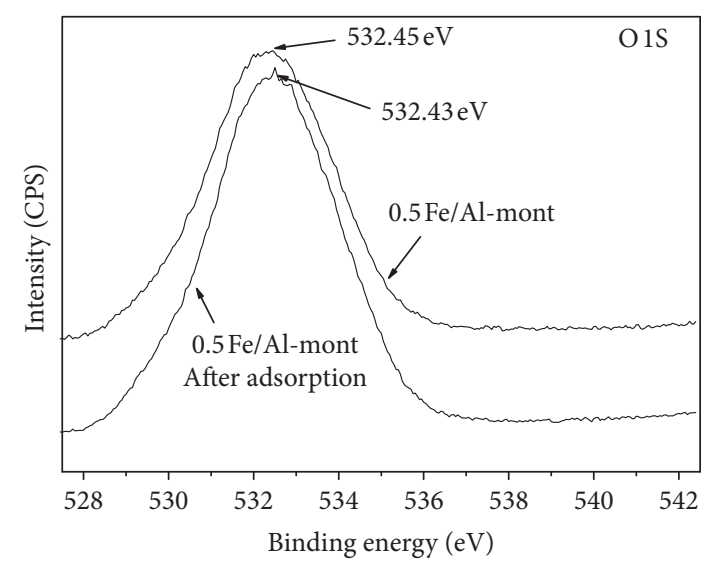

(b)

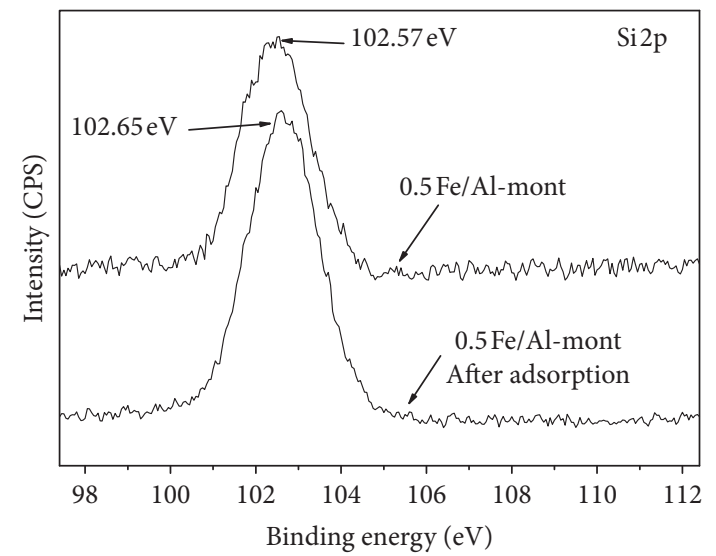

(d)

Figure 7: XPS of O1s, Al 2p, Si 2p, and Fe 2p of 0.5Fe/Al-Mont.

adsorption. At higher ZEA concentrations, the competition for adsorption sites on the adsorbents increases significantly, thereby increasing adsorption. According to Figure 11, the ZEA adsorption capacities are ranked as follows, regardless of the ZEA initial concentration: Mont $<<1.5 \mathrm{OH} / \mathrm{Fe}$-Mont $<<\mathrm{OH} / \mathrm{Al}$-Mont $<0.5 \mathrm{Fe} / \mathrm{Al}$-Mont. This result indicates that the ZEA adsorption capacity of Mont increased significantly after modification; therefore, the hydrolysed $\mathrm{Fe}$, hydrolysed $\mathrm{Al}$, and hydrolysed $\mathrm{Fe} / \mathrm{Al}$ pillar modification of Mont significantly increased the ZEA adsorption capacity.

The experimental data obtained were modelled using a Langmuir adsorption isotherm (1) and a Freundlich adsorption isotherm [31]:

$$
\begin{aligned}
& q_{e}=q_{\max } \frac{K_{L} C_{e}}{1+K_{L} C_{e}}, \\
& q_{e}=K_{F} c_{e}^{1 / n} .
\end{aligned}
$$

In the above equation, $q_{e}$ is the equilibrium adsorption capacity $(\mathrm{mg} / \mathrm{g}), C_{e}$ is the equilibrium concentration $(\mathrm{mg} / \mathrm{L})$, $q_{\max }$ is the maximum adsorption capacity $(\mathrm{mg} / \mathrm{g}), K_{L}$ is the Langmuir adsorption coefficient $(\mathrm{L} / \mathrm{mg})$, and $K_{F}$ is the Freundlich adsorption coefficient $\left(\mathrm{mg}^{1-1 / n} \cdot \mathrm{L}^{1 / n} \cdot \mathrm{g}^{-1}\right)$. The parameters used in both Langmuir and Freundlich isotherms are summarized in Table 2.

It can be inferred from Table 2 that the Freundlich model $\left(r^{2} \geq 0.95\right)$ is a better fit than the Langmuir model $\left(r^{2}<0.05\right)$ for Mont, $1.5 \mathrm{OH} / \mathrm{Fe}-\mathrm{Mont}, \mathrm{OH} / \mathrm{Al}$-Mont, and $1.5 \mathrm{Fe} / \mathrm{Al}-\mathrm{Mont}$ regarding the ZEA adsorption. The Langmuir model is a description of a particle monolayer adsorption with identical adsorption sites, and every adsorption process is completely independent. From Table 1, it is apparent that the Langmuir adsorption model is not representative of both pristine Mont and modified Mont, which indicates that the ZEA adsorption process is complex in multimolecular layer adsorption. This result agrees with recent research, which also suggests that ZEA undergoes multilayer adsorption in which both the surface and interlayer spacing of the Mont are available adsorption sites. As a result, ZEA may adsorb onto the surface of adsorbent materials through surface complexation reactions or through spatial interpolation layer adsorption, which agrees with the current data and suggests that the Freundlich model is a better reflection of the ZEA adsorption processes on the surface of Mont. In the Freundlich model, the ease of adsorption is described by the parameter $1 / n$, where a value $<1$ or close to 1 indicates high adsorption probability. This also explains 


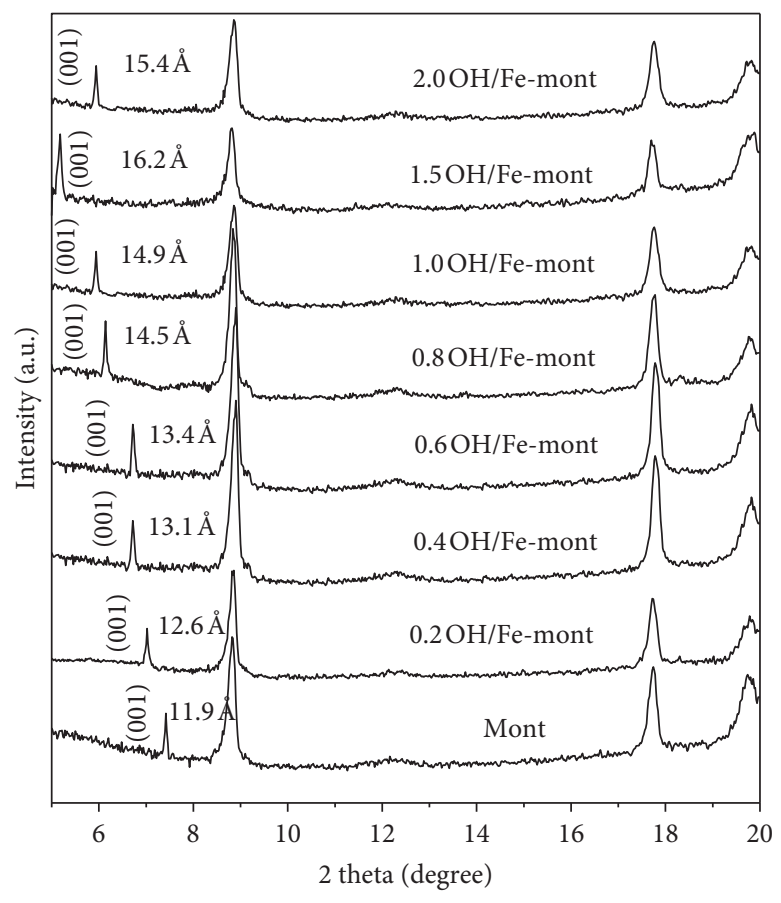

(a)

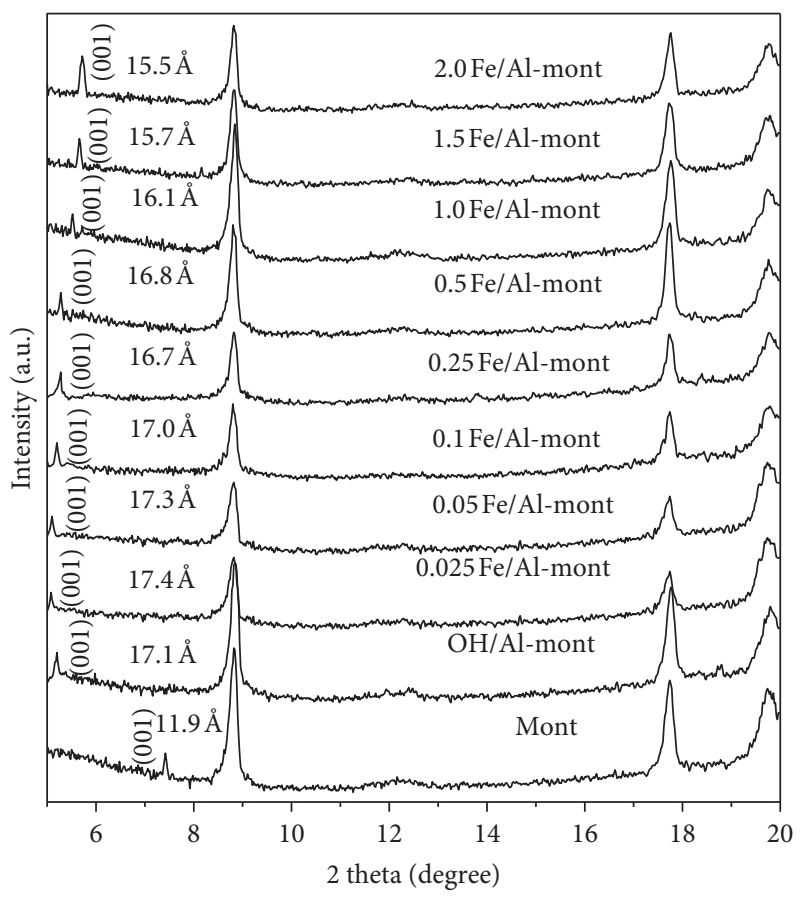

(b)

FIgURe 8: X-ray diffraction patterns of hydroxyl-Fe-Al-pillared Mont.

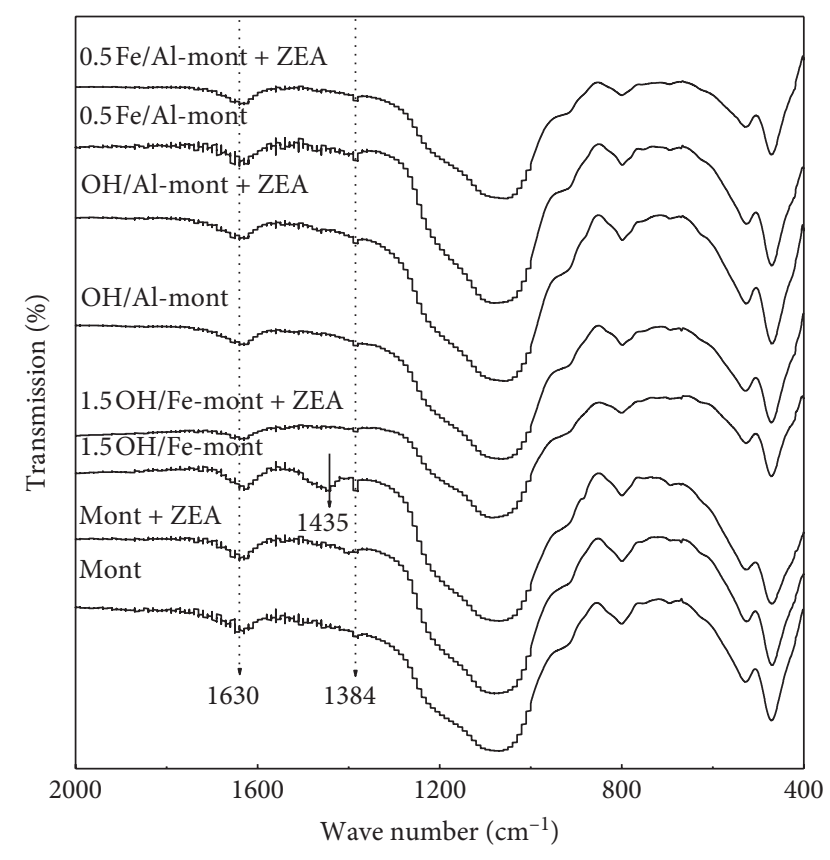

FIGURE 9: FT-IR spectra before and after ZEA adsorption (+ZEA represents adsorption) on hydroxyl-Fe-Al-pillared Mont.

that modified Mont can be used as an effective adsorbent to remove ZEA [32-34].

3.9. Effects of $\mathrm{pH}$ and Temperature. The effect of $\mathrm{pH}$ on the ZEA adsorption capacity is illustrated in Figure 12, which shows that between the $\mathrm{pH}$ range of $2-8$, the adsorption capacity increases with increasing $\mathrm{pH}$ value, and the capacity of modified Mont is significantly greater than pristine Mont. The correlation between $\mathrm{pH}$ value and adsorption capacity is represented in two stages: when $\mathrm{pH}<8$, the adsorption capacity increases with increasing $\mathrm{pH}$ value; when $\mathrm{pH}>8$, the adsorption capacity decreases with increasing $\mathrm{pH}$. This observation can be attributed to the fact that ZEA possesses a chemical structure ( is considered a weak acid. Because $\mathrm{pK}_{\mathrm{a} 1}$ of ZEA is 7.62, under conditions where $\mathrm{pH}<7.62$, the ZEA molecules are positively charged; therefore, under low $\mathrm{pH}$ conditions, the number of excess $\mathrm{H}^{+}$ions in solution reduces the number of available adsorption sites within the interlayer spacing of Mont, thus reducing the overall adsorption of ZEA $[35,36]$. With increasing $\mathrm{pH}$, the number of available adsorption sites increases up to a maximum $\mathrm{pH}$ of 8 . With further increases in $\mathrm{pH}$, the presence of hydroxide in solution begins to break down the polymer adsorption characteristics, thereby reducing the overall adsorption capacity of Mont.

The effect of solution temperature on the ZEA adsorption capacity of Mont is depicted in Figure 13. Initially, the ZEA adsorption capacity increases with increasing temperature and peaks at a temperature of $35^{\circ} \mathrm{C}$, after which the adsorption capacity decreases with further increases in temperature. This result can be attributed to the increase in reactivity of the unsaturated active sites in Mont with increasing temperature within the range of $15^{\circ} \mathrm{C}$ to $35^{\circ} \mathrm{C}$, which is conducive to the formation of a bond with ZEA. In contrast, at temperatures above $35^{\circ} \mathrm{C}$, excess heat can cause bond breakage, leading to lower adsorption. Because the $\mathrm{pH}$ 


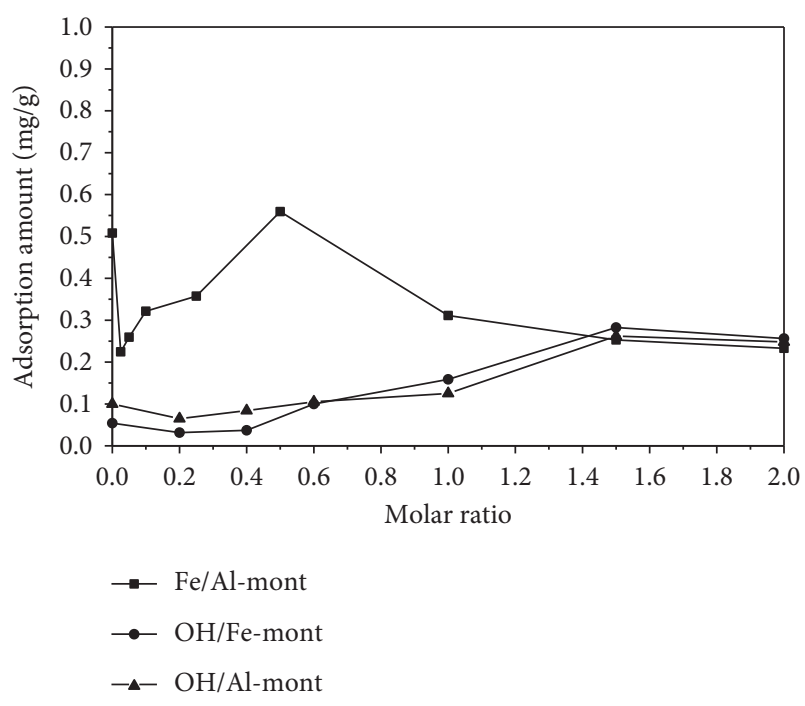

Figure 10: Effect of varying the $\mathrm{OH} / \mathrm{Fe}, \mathrm{OH} / \mathrm{Al}$, and $\mathrm{Fe} / \mathrm{Al}$ molar ratios on the ZEA adsorption capacity.

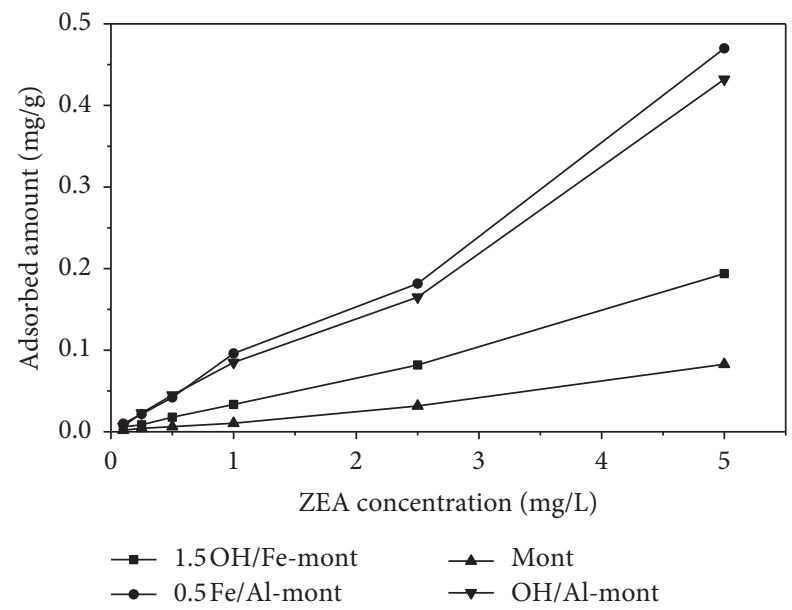

FIGURE 11: Relationship diagram between adsorption capacity and equilibrium concentration of ZEA.

TABLE 2: Model parameters of both Langmuir and Freundlich adsorption isotherms for ZEA.

\begin{tabular}{lcccccc}
\hline \multirow{2}{*}{ Adsorbing material } & \multicolumn{3}{c}{ Langmuir } & \multicolumn{3}{c}{ Freundlich } \\
& $r^{2}$ & $K_{L}$ & $q_{\max }(\mathrm{mg} / \mathrm{g})$ & $r^{2}$ & $K_{F}$ & $1 / n$ \\
\hline Mont & 0.01 & 0.01 & 1.50 & 0.96 & 0.02 & 0.87 \\
1.5OH/Fe-Mont & 0.02 & 0.02 & 2.38 & 0.98 & 0.04 & 0.91 \\
0.5Fe/Al-Mont & 0.04 & 0.04 & 3.73 & 0.98 & 0.11 & 1.04 \\
OH/Al-Mont & 0.01 & 0.01 & 10.57 & 0.97 & 0.14 & 1.00 \\
\hline
\end{tabular}

value in livestock is in the range of 6.5-7.5, and the body temperature is $37-42^{\circ} \mathrm{C}$, the use of Mont as an adsorbent in vivo can be considered because the optimum performance parameters of Mont lie within this range [33-37].

3.10. Adsorption Kinetics. Figure 14 displays the ZEA adsorption capacity of Mont as a function of time. It can be observed that, at any point in time, the adsorption capacities

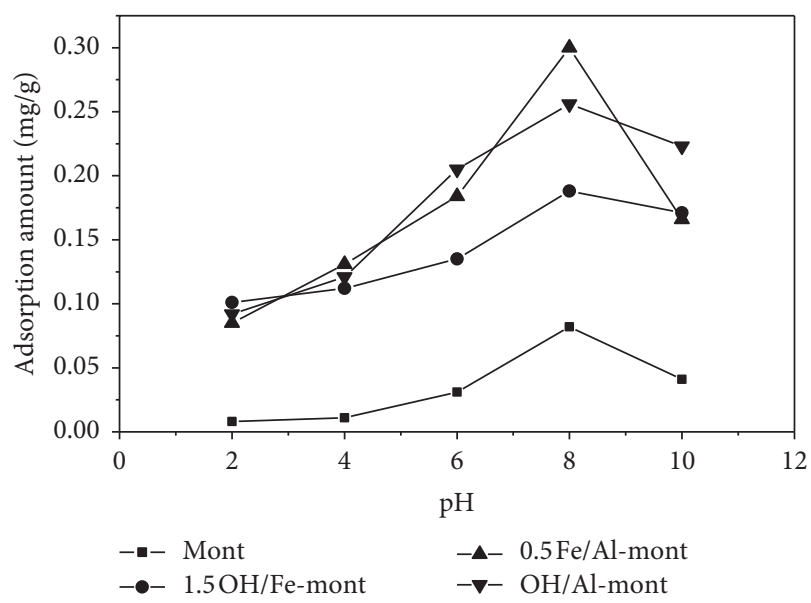

Figure 12: Effect of $\mathrm{pH}$ on the ZEA adsorption capacity of Mont.

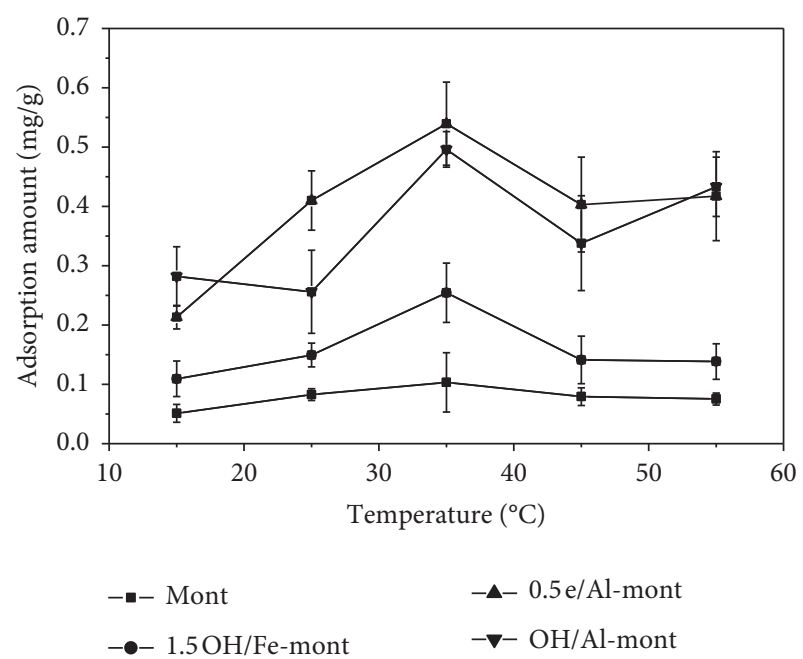

FIGURE 13: Effect of temperature on the ZEA adsorption capacity of Mont.

of the adsorbents are consistently ranked as follows: Mont $<<1.5 \mathrm{OH} / \mathrm{Fe}-\mathrm{Mont}<<\mathrm{OH} / \mathrm{Al}-\mathrm{Mont}<0.5 \mathrm{Fe} / \mathrm{Al}-$

Mont. The relationship between the adsorption quantity and time can be described using a kinetic model, and it was found that a pseudo-second-order kinetic model best fits the experimental data (Figure 14). This model has been widely used in the solution adsorption of ZEA and other pollutants $[38,39]$.

$$
\begin{aligned}
& q_{t}=\frac{k q_{e}^{2} t}{1+k q_{e} t} \\
& \frac{t}{q_{t}}=\frac{1}{k q_{e}^{2}}+\frac{1}{q_{e}} t .
\end{aligned}
$$

In the above equation, $k\left(\mathrm{~g} \cdot \mathrm{mg}^{-1} \cdot \mathrm{h}^{-1}\right)$ is the adsorption rate constant, $q_{e}\left(\mathrm{mg}^{-\mathrm{g}^{-1}}\right)$ is the equilibrium adsorption capacity, and $q_{t}\left(\mathrm{mg}^{-1} \mathrm{~g}^{-1}\right)$ is the adsorption quantity at time $t$. Equation (3) is rearranged to a linear equation, where $k q_{e}^{2}$ $\left(\mathrm{mg} \cdot \mathrm{g}^{-1} \cdot \mathrm{h}^{-1}\right)$ is the initial adsorption rate, and by 


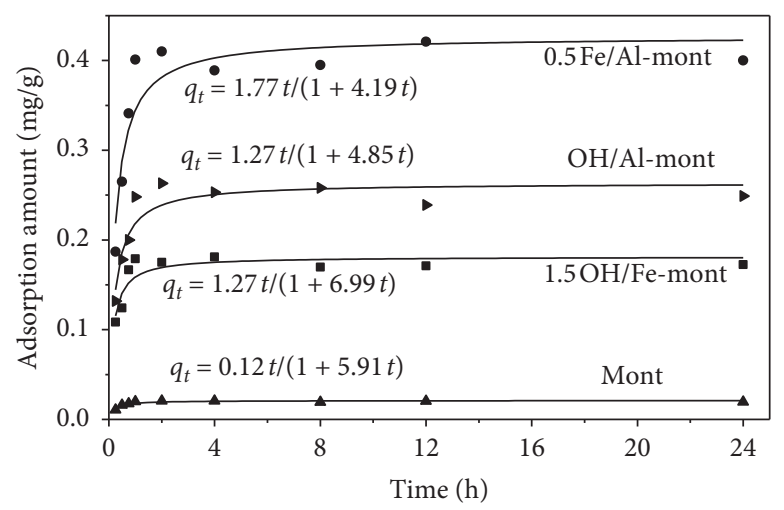

FIgUre 14: ZEA adsorption kinetics of Mont and pillared Mont.

TABLE 3: Parameters of pseudo-second-order equation for adsorption of ZEA.

\begin{tabular}{lcccc}
\hline Adsorbing material & \multicolumn{4}{c}{ Pseudo-second-order kinetic model } \\
& $r^{2}$ & $\begin{array}{c}k q_{e}^{2} \\
\left(\mathrm{mg} \cdot \mathrm{g}^{-1} \cdot \mathrm{h}^{-1}\right)\end{array}$ & $\begin{array}{c}K \\
\left(\mathrm{~g} \cdot \mathrm{mg}^{-1} \cdot \mathrm{h}^{-1}\right)\end{array}$ & $\begin{array}{c}q_{e} \\
\left(\mathrm{mg} \cdot \mathrm{g}^{-1}\right)\end{array}$ \\
\hline Mont & 0.999 & 0.12 & 281.4 & 0.02 \\
1.5OH/Fe-Mont & 0.995 & 1.27 & 38.5 & 0.18 \\
OH/Al-Mont & 0.999 & 3.26 & 52.6 & 0.25 \\
0.5Fe/Al-Mont & 0.999 & 3.68 & 22.3 & 0.41 \\
\hline
\end{tabular}

substituting the relevant parameters into equation (4), various kinetic parameters are obtained (summarized in Table 3). From Table 3, the following relationships are apparent: the correlation coefficient $r^{2}>0.99$; the initial adsorption rates are ranked as Mont $\left(0.12 \mathrm{mg} \cdot \mathrm{g}^{-1} \cdot \mathrm{h}^{-1}\right)$ $<<1.5 \mathrm{OH} / \mathrm{Fe}-$ Mont $\quad\left(1.27 \mathrm{mg} \cdot \mathrm{g}^{-1} \cdot \mathrm{h}^{-1}\right)<<\mathrm{OH} / \mathrm{Al}-\mathrm{Mont}$ $\left(3.26 \mathrm{mg} \cdot \mathrm{g}^{-1} \cdot \mathrm{h}^{-1}\right)<0.5 \mathrm{Fe} / \mathrm{Al}-\mathrm{Mont} \quad\left(3.68 \mathrm{mg} \cdot \mathrm{g}^{-1} \cdot \mathrm{h}^{-1}\right)$; the equilibrium adsorption capacity $q_{e}$ is also ranked as Mont $\left(0.02 \mathrm{mg} \cdot \mathrm{g}^{-1}\right)<<1.5 \mathrm{OH} / \mathrm{Fe}-\mathrm{Mont} \quad\left(0.18 \mathrm{mg} \cdot \mathrm{g}^{-1}\right)<\mathrm{OH} / \mathrm{Al}-$ Mont $\left(0.25 \mathrm{mg} \cdot \mathrm{g}^{-1}\right)<<0.5 \mathrm{Fe} / \mathrm{Al}-$ Mont $\left(0.41 \mathrm{mg} \cdot \mathrm{g}^{-1}\right)$, which suggests that modified Mont exhibited significantly improved solution adsorption of ZEA and is an excellent candidate as a ZEA adsorbent, especially species with Fe/Alcomposite pillars.

\section{Conclusions}

(1) The XRD analysis revealed that the interlayer spacing $\mathrm{d}(001)$ of hydrolysed Fe-pillared Mont increases gradually with increasing $\mathrm{OH} / \mathrm{Fe}$ molar ratios, up to a ratio of $\leq 1.5$, while the $\mathrm{d}(001)$ decreases with increasing $\mathrm{Fe} / \mathrm{Al}$ molar ratios in hydrolysedFe/Al-composite-pillared Mont. The amplification of Fe-dominant pillared Mont interlayer spacing is the main reason for the observed increases in the adsorption capacity of ZEA. However, aluminium pillared Monts possess a relatively stable Keggin structure in which the adsorption capacity is not dictated by interlayer spacing. The FT-IR analysis clearly indicated that the mechanism in which ZEA and $\mathrm{Al}$ ions enter
Mont is predominantly due to cationic exchange, whereas the migration of hydrolysed Fe into the interlayer spacing of Mont is not governed by ion exchange.

(2) The difference in the ZEA adsorption capacities between hydrolysed $\mathrm{Fe}$ and $\mathrm{Al}$ compared to a composite-pillared structure can be ranked as follows: Mont $\quad(0.05 \mathrm{mg} / \mathrm{g})<<1.5 \mathrm{OH} / \mathrm{Fe}-$ Mont $(0.28 \mathrm{mg} / \mathrm{g})<<\mathrm{OH} / \mathrm{Al}-\mathrm{Mont} \quad(0.51 \mathrm{mg} / \mathrm{g})<0.5 \mathrm{Fe} /$ Al-Mont $(0.56 \mathrm{mg} / \mathrm{g})$; both $0.5 \mathrm{Fe} / \mathrm{Al}-\mathrm{Mont}$ and $\mathrm{OH} /$ Al-Mont possess the greatest adsorption capacity, which is approximately an order of magnitude greater than pristine Mont. Hydroxyl Fe Mont with a molar ratio of $1.5(1.5 \mathrm{OH} / \mathrm{Fe}-\mathrm{Mont})$ exhibited a 5fold increase in adsorption capacity compared to pristine Mont.

(3) Adsorption isotherm studies confirmed that the Freundlich adsorption model well represents $\left(r^{2}>0.95\right)$ the ZEA adsorption of Mont. In the model, the parameter $1 / n<1$ gave a value between 0.8 and 1 , which indicates that $\mathrm{ZEA}$ is readily adsorbed.

(4) The ZEA adsorption capacity increases with increasing $\mathrm{pH}$ at $\mathrm{pH}$ values $\leq 8$. At $\mathrm{pH}>8$, the adsorption capacity decreases with further increases in $\mathrm{pH}$. The optimum performance temperature was found to be within a biological range of approximately $35^{\circ} \mathrm{C}$.

(5) ZEA adsorption onto Mont was found to equilibrate within an hour. Kinetic studies and parameters demonstrated that the adsorption process can be described using pseudo-second-order kinetics (correlation coefficient $R^{2}>0.99$ ). The equilibrium adsorption capacity $q_{e}$ of the various adsorbents was found to be Mont $\left(0.02 \mathrm{mg} \cdot \mathrm{g}^{-1}\right)<<1.5 \mathrm{OH} / \mathrm{Fe}-$ Mont $\left(0.18 \mathrm{mg} \cdot \mathrm{g}^{-1}\right)<\mathrm{OH} / \mathrm{Al}-$ Mont $\left(0.25 \mathrm{mg} \cdot \mathrm{g}^{-1}\right)<<0.5 \mathrm{Fe} /$ Al-Mont $\left(0.41 \mathrm{mg} \cdot \mathrm{g}^{-1}\right)$.

The mechanisms of interaction between pristine Mont and ZEA and between hydroxyl-Fe-Al-pillared Mont and ZEA were elucidated in this study, which can be used to improve the removal efficacy of mycotoxins. The use of hydroxyl-pillared Mont in the in vivo removal of ZEA from 
animal gastrointestinal tracts warrants further investigation. Hydroxyl-iron, hydroxyl-aluminum, and hydroxyl-aluminum-iron are supported on montmorillonite and have a large amount of positive charge on the surface. The ZEA molecule has two phenolic hydroxyl groups, which can be regarded as weakly acidic molecules. When the $\mathrm{pH}$ is 8 , ZEA dissociates to a greater extent. The anions formed by ZEA dissociation can chemisorb with the positive charge on the side of montmorillonite. The increase in $\mathrm{pH}$ makes the competitive adsorption of hydrogen ions and ZEA weaker, so the amount of ZEA adsorbed by the adsorbent gradually increases.

\section{Data Availability}

The data used to support the findings of this study are included within the article.

\section{Conflicts of Interest}

The authors declare that there are no conflicts of interest regarding the publication of this paper.

\section{Acknowledgments}

This study was supported by the Natural Science Foundation of China (Item no. 21303019) and College of Environment and Resources, Fuzhou University. The authors thank Center for Analysis and Testing, Fuzhou University, for helping during FT-IR analyses and in collecting the X-ray diffraction data.

\section{Supplementary Materials}

Graphical abstract. (Supplementary Materials)

\section{References}

[1] J. Li, J. Cai, L. Zhong, H. Cheng, H. Wang, and Q. Ma, "Adsorption of reactive red 136 onto chitosan/montmorillonite intercalated composite from aqueous solution," Applied Clay Science, vol. 167, pp. 9-22, 2019.

[2] J. Li, J. Cai, L. Zhong, H. Wang, H. Cheng, and Q. Ma, "Adsorption of reactive dyes onto chitosan/montmorillonite intercalated composite: multi-response optimization, kinetic, isotherm and thermodynamic study," Water Science and Technology, vol. 77, no. 11, pp. 2598-2612, 2018.

[3] M. F. Ma, N. L. Ovchinnikov, N. S. Karasev, N. E. Kochkina, A. V. Agafonov, and A. V. Vinogradov, "Photocatalytic and adsorption properties of $\mathrm{TiO}_{2}$-pillared montmorillonite obtained by hydrothermally activated intercalation of titanium polyhydroxo complexes," Beilstein Journal of Nanotechnology, vol. 9, pp. 364-378, 2018.

[4] B. D. Zhu, J. Y. Zhang, C. H. Lin, H.-L. Chen, and J. Wang, "Nonisothermal crystallization kinetics of ethylene vinyl alcohol copolymer with poly(oxypropylene)diamine intercalated montmorrilonite," Journal of Macromolecular Science Part B, vol. 57, no. 5, pp. 333-347, 2018.

[5] M. E. Savard, "Mycotoxins-an introduction," Stewart Postharvest Review, vol. 4, no. 6, pp. 1-6, 2008.
[6] B. B. Jarvis and J. D. Miller, "Mycotoxins as harmful indoor air contaminants," Applied Microbiology and Biotechnology, vol. 66, no. 4, pp. 367-372, 2005.

[7] A. Yuhong, Z. Xiaotao, W. Ximing et al., "Nano@lignocellulose intercalated montmorillonite as adsorbent for effective $\mathrm{Mn}$ (II) removal from aqueous solution," Scientific Reports, vol. 8, no. 1, Article ID 10863, 2018.

[8] C. P. Wild and Y. Y. Gong, "Mycotoxins and human disease: a largely ignored global health issue," Carcinogenesis, vol. 31, no. 1, pp. 71-82, 2010.

[9] S. D. Upadhaya, M. A. Park, and J. K. Ha, "Mycotoxins and their biotransformation in the rumen: a review," AsianAustralasian Journal of Animal Sciences, vol. 23, no. 9, pp. 1250-1260, 2010.

[10] Q. R. Wei and Z. R. Yu, "The main types and their harms of mycotoxins," Technical Advisor for Animal Husbandry, vol. 128 , no. 5 , p. 149,2012 , in Chinese.

[11] B. Caterina and G. D’Angelo, “Aggregation behavior of pluronic F127 solutions in presence of chitosan/clay nanocomposites examined by dynamic light scattering," Journal of Colloid \& Interface Science, vol. 15, no. 542, pp. 289-295, 2019.

[12] IARC, Monographs on the Evaluation of Carcinogenic Risk to Humans, World Health Organisation, Lyon, France, 1993.

[13] R. Wang, M. Zhaohua, and Z. Zhang, "Investigation of mould toxin pollution of feed and feedstuff," Feed Industry, vol. 24, no. 7, pp. 53-54, 2003, in Chinese.

[14] Z. Chen, S. Zhang, Y. Liu et al., "Synthesis and fabrication of g- $\mathrm{C}_{3} \mathrm{~N}_{4}$-based materials and their application in elimination of pollutants," Science of the Total Environment, vol. 731, no. 20, p. 139054, 2020.

[15] X. Wang, Li Xing, J. Wang, and H. Zhu, "Recent advances in carbon nitride-based nanomaterials for the removal of heavy metal ions from aqueous solution," Journal of Inorganic Materials, vol. 35, no. 3, pp. 260-270, 2020.

[16] B. Hu, Y. Ai, J. Jin, T. Hayat et al., "Efficient elimination of organic and inorganic pollutants by biochar and biocharbased materials," Biochar, vol. 2, no. 1, pp. 47-64, 2020.

[17] M. Alsaedi, H.-M. Müller, M. Rüfle, S. Suchy, S. Plank, and W. Drochner, "Natural occurrence of 16 fusarium toxins in grains and feedstuffs of plant origin from Germany," Mycopathologia, vol. 161, no. 1, pp. 43-52, 2006.

[18] G. Wang, Z. J. Xu, and S. Zheng, "Surface functionalization of montmorillonite with chitosan and the role of surface properties on its adsorptive performance: a comparative study on mycotoxins adsorption," Langmuir, vol. 36, no. 10, pp. 2601-2611, 2020.

[19] A. J. Ramos, E. Hernández, J. M. Plá-Delfina, and M. Merino, "Intestinal absorption of zearalenone and in vitro study of non-nutritive sorbent materials," International Journal of Pharmaceutics, vol. 128, no. 1-2, pp. 129-137, 1996.

[20] Q. Yang, W. Wentao, Z. Hui, Y. Dai, H. Hou, and H. Dong, "Effects of organic modification of montmorillonite on the properties of hydroxypropyl di-starch phosphate films prepared by extrusion blowing," Materials, vol. 11, no. 7, Article ID 1064, 2018.

[21] S. L. Lemke, P. G. Grant, and T. D. Phillips, "Adsorption of zearalenone by organophilic montmorillonite clay," Journal of Agricultural and Food Chemistry, vol. 46, no. 9, pp. 37893796, 1998.

[22] P. Ac, "Mycotoxins and animal health," Advances in Veterinary Science \& Comparative Medicine, vol. 25, no. 2, pp. 185-243, 1981. 
[23] Z. M. Bekci, M. K. Antep, M. Merdivan, and K. Yurdakoç, "Zearalenone removal in synthetic media and aqueous part of canned corn by montmorillonite K10 and pillared montmorillonite K10," Journal of Food Protection, vol. 74, no. 6, pp. 954-959, 2011.

[24] M. A. Diekman and M. L. Green, "Mycotoxins and reproduction in domestic livestock," Journal of Animal Science, vol. 70, no. 5, pp. 1615-1627, 1992.

[25] O. Akin and F. Tihminlioglu, "Effects of organo-modified clay addition and temperature on the water vapor barrier properties of polyhydroxy butyrate homo and copolymer nanocomposite films for packaging applications," Journal of Polymers and the Environment, vol. 26, no. 3, pp. 1121-1132, 2018.

[26] L. Zeng and S. P. Wang, "Adsorption of zearalenone by montmorillonite," Advanced Materials Research, vol. 683, pp. 343-347, 2013.

[27] H. P. Corporation, "Preparation and characterization of montmorillonite intercalation compounds with quaternary ammonium surfactant: adsorption effect of zearalenone," Journal of Nanomaterials, vol. 2014, Article ID 167402, 7 pages, 2014

[28] J. Feng, M. Shan, H. Du, X. Han, and Z. Xu, "In vitro adsorption of zearalenone by cetyltrimethyl ammonium bromide-modified montmorillonite nanocomposites," Microporous and Mesoporous Materials, vol. 113, no. 1-3, pp. 99-105, 2008.

[29] A. Daković, S. Matijašević, G. E. Rottinghaus, V. Dondur, T. Pietrass, and C. F. M. Clewett, "Adsorption of zearalenone by organomodified natural zeolitic tuff," Journal Colloid Interface Science, vol. 311, no. 1, pp. 8-13, 2007.

[30] C.-s. Sun, Preparation, Characterization and Adsorption Behaviors of the Inorganic Pillared Bentonites and its Application in Wastewater Treatment, Xi'an University of Architecture and Technology, Xi'an, China, 2008, in Chinese.

[31] I. Pálinkó, K. Lázár, I. Hannus, and I. Kirisci, “Step towards nanoscale Fe moieties: intercalation of simple and keggin-type iron-containing ions in-between the layers of Na-montmorillonite," Journal of Physics and Chemistry of Solids, vol. 57, no. 6-8, pp. 1067-1072, 1996.

[32] E. G. Rightor, M. S. Tzou, and T. J. Pinnavaia, "Iron oxide pillared clay with large gallery height: synthesis and properties as a fischer-tropsch catalyst," Journal of Catalysis, vol. 130, no. 91, pp. 29-40, 1991.

[33] R. Herrera and M. Peech, "Reaction of montmorillonite with iron(III)," Soil Science Society of America Journal, vol. 34, no. 5, pp. 740-742, 1970.

[34] P. Wu, "Microstructure characteristic of polyhydroxy-Fe-Al pillared montmorillonite," Journal of the Chinese Ceramics Society, vol. 31, no. 10, pp. 1016-1020, 2003.

[35] P. Yuan, F. Wang, W. Xiao et al., "Characterization of iron delaminated pillared montmorillonite: a primary study," Journal of Mineralogy and Petrology, vol. 25, no. 3, pp. 37-40, 2005, in Chinese.

[36] H. Shao, Y. Liu, Ji Kejian et al., "Preparation and structure characterization of hydroxyl Al pillared montmorillonite," Chemical Analysis And Meterage, vol. 24, no. 1, pp. 61-63, 2015.

[37] C. Zhang, Y. Ma, B. Feng et al., "Effects of montmorillonite on structures and properties of injection-molded polypropylene," Journal of Applied Polymer Science, vol. 136, no. 18, Article ID 47442, 2019.
[38] L. Sciascia, M. L. Turco Liveri, and M. Merli, "Kinetic and equilibrium studies for the adsorption of acid nucleic bases onto K10 montmorillonite," Applied Clay Science, vol. 53, no. 4, pp. 657-668, 2011.

[39] M. Goswami, L. Borah, D. Mahanta, and P. Phukan, "Equilibrium modeling, kinetic and thermodynamic studies on the adsorption of $\mathrm{Cr}(\mathrm{VI})$ using activated carbon derived from matured tea leaves," Journal of Porous Materials, vol. 21, no. 6, pp. 1025-1034, 2014. 